Thorax (1946), 1, 146.

\title{
SPREADING SUPPURATIVE PNEUMONITIS
}

\author{
BY
}

\author{
T. HOLMES SELLORS, L. G. BLAIR, L. E. HOUGHTON, \\ VERNON C. THOMPSON, D. M. PRYCE
}

From the Thoracic Surgical Unit, E.M.S., Harefield

Pulmonary cavitation not associated with specific inflammations of the lung has been increasingly recognized in recent years, and we now feel justified in presenting a study of a condition which we describe as "spreading suppurative pneumonitis." To differentiate this condition from others associated with cavity formation, we also suggest a new classification of excavating lung lesions. The generic term "pneumonitis" is used in preference to "pneumonia" because the latter has become associated with specific types of lung consolidation. The material for this study has been obtained from admissions to the Harefield Thoracic Surgical Unit over a period of five years. All cases admitted as pneumonitis or lung abscess were examined, and 27 of these were chosen as fulfilling certain criteria, namely, spreading pneumonitic changes associated with cavity formation, and a productive cough with purulent sputum. Cases in which there was any doubt whether the lesion belonged to the group under discussion were excluded.

\section{Radiological Changes}

The most accurate method of studying the course of the disease is by radiographs, and radiological investigations enabled us to watch and describe the changes encountered. These changes were correlated with the usual clinical examinations. For analysis of the radiological appearances, 23 of the 27 cases were selected, either because they had been followed radiologically from the time of their admission to Harefield-practically from the onset-or because radiographs taken early in the disease at other hospitals were available. We were thus able to trace the radiological changes of every patient in detail.

In the early stages a homogeneous opacity, not completely segmental in distribution, suggested consolidation. Later a central translucent patch in the opaque area indicated softening and excavation; but cavitation was not seen as early as in an acute putrid lung abscess. Massive consolidation was the most striking feature, with cavitation appearing as a relatively minor incident; and this also contrasts with the acute abscess. The site of the lesion differed from that 


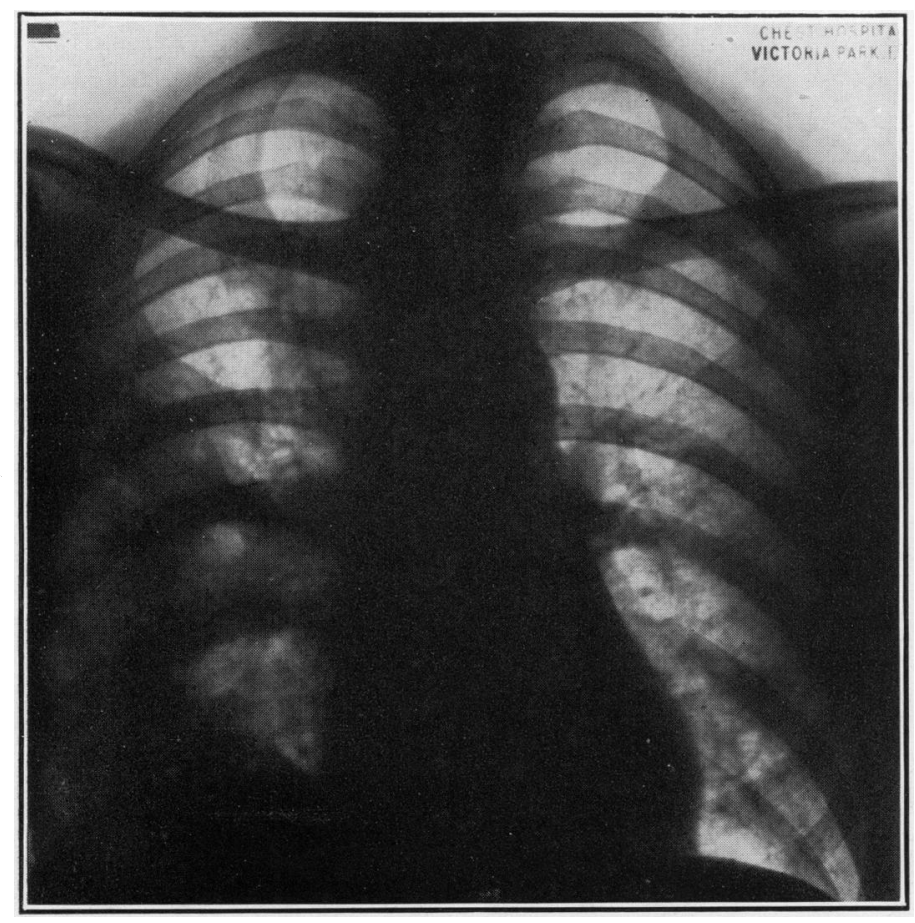

Fig. 1.-Case 5, Oct. 12, 1938. There is consolidation and collapse in the right mid and lower zones.

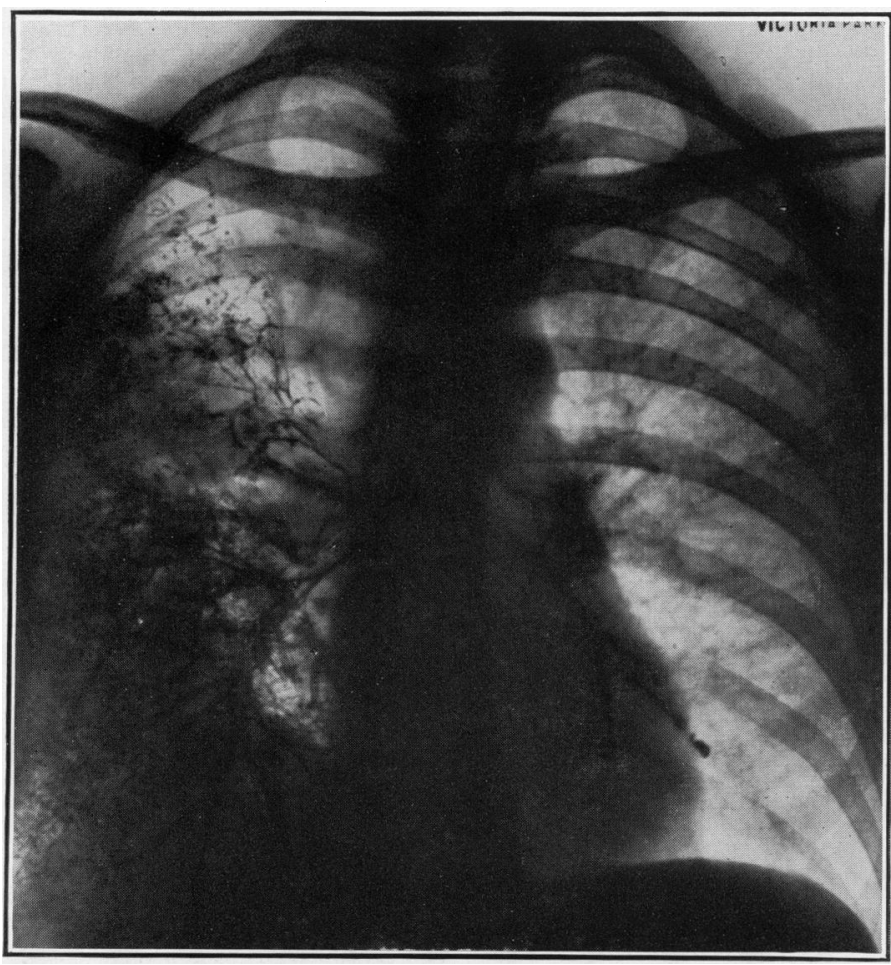

Fig. 3.-Case 5, Oct. 26, 1938. Bronchogram shows a normal right bronchial tree, with the exception of lack of filling in the region of the lesion in the mid zone.

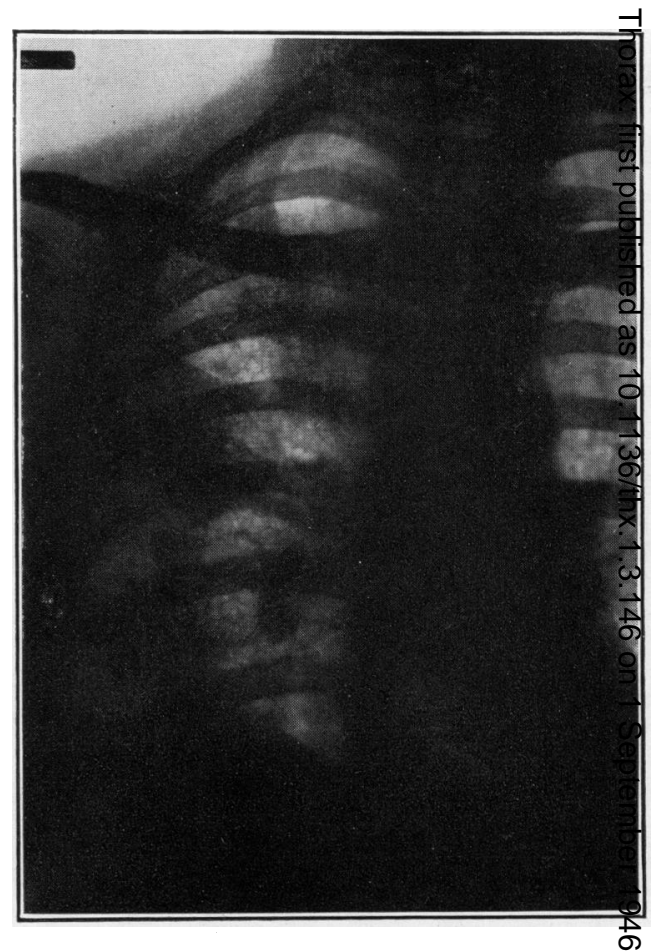

FIG. 2.-Case 5, Oct. 20, 1938. Eight days later; there is some clearing of the lesion at the base.

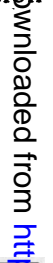

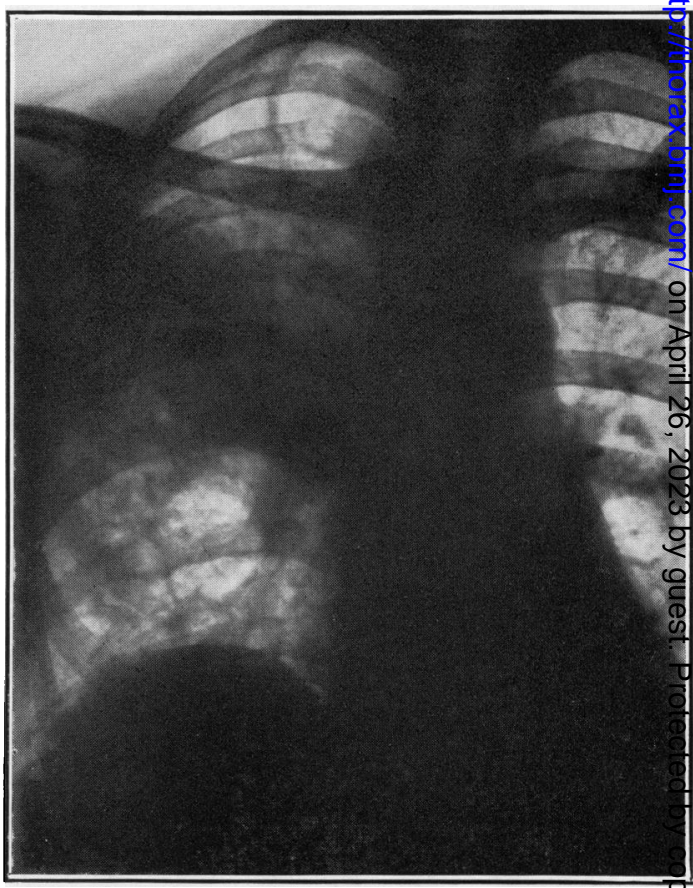

FIG. 4.-Case 5, Feb. 1, 1939. The base is agaī clearer, but there is an extension of the lesion in the base of the upper lobe. 


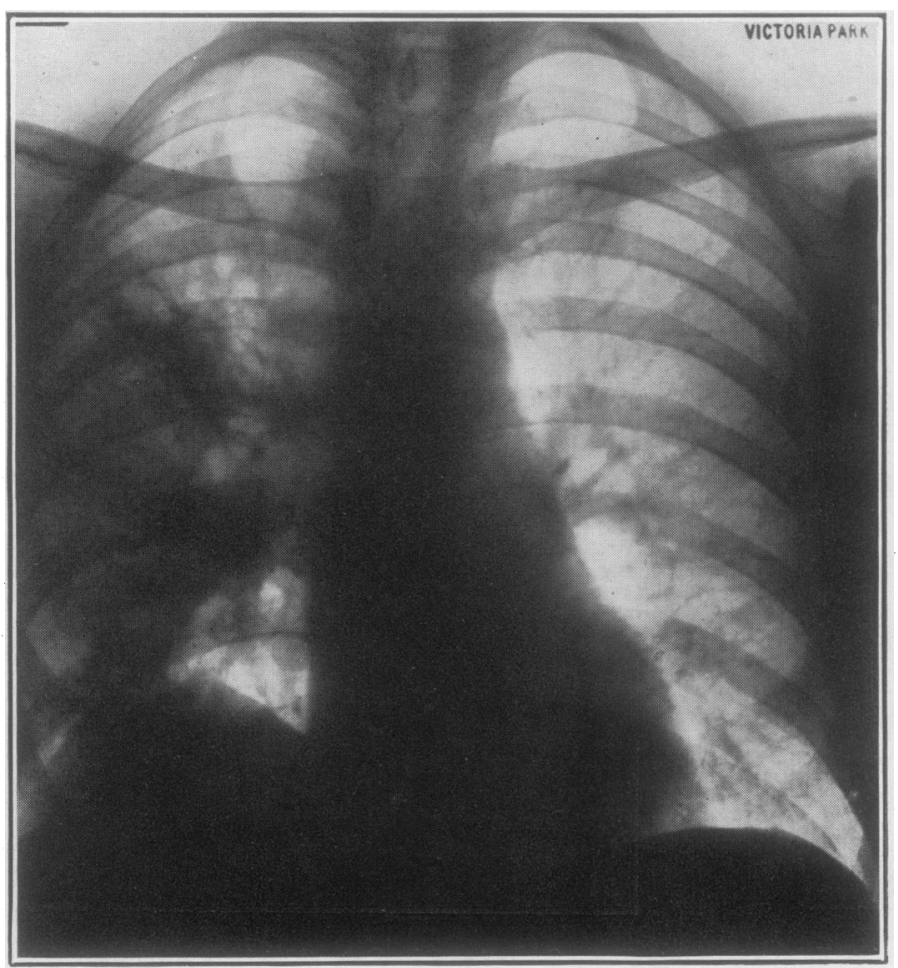

Fig. 5.-Case 5, Aug. 10, 1939. Six months later, there is again consolidation and collapse at the base.

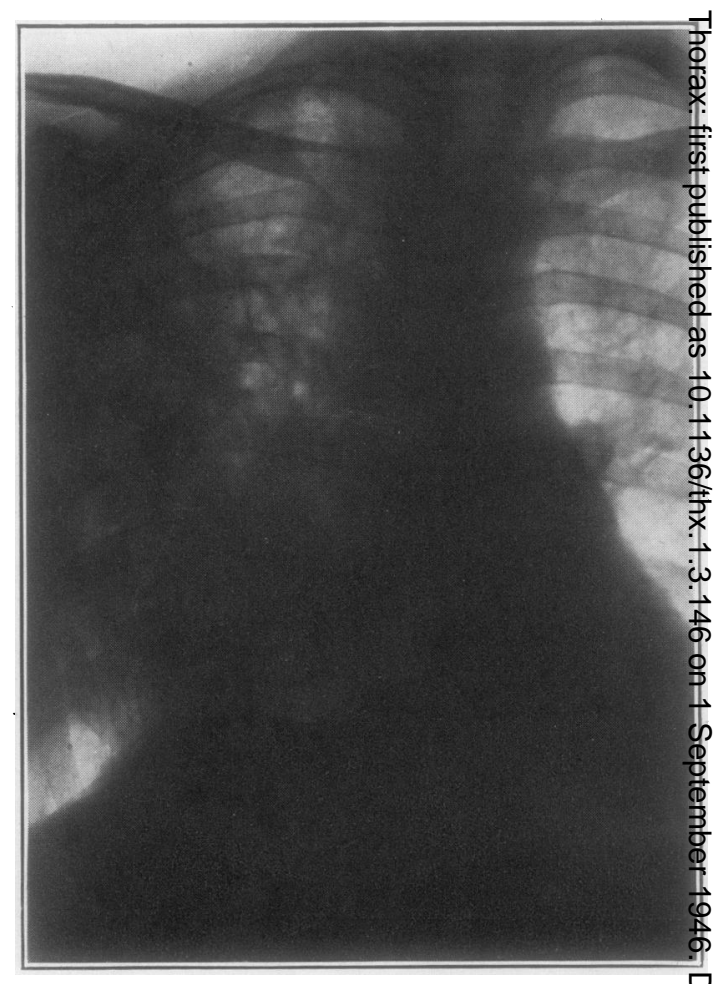

Fig. 6.-Case 5, June 21, 1943. Three and a halfo years later; there is a thin-walled cavity ats the apex, and there is further consolidationo at the base, with a cavity.

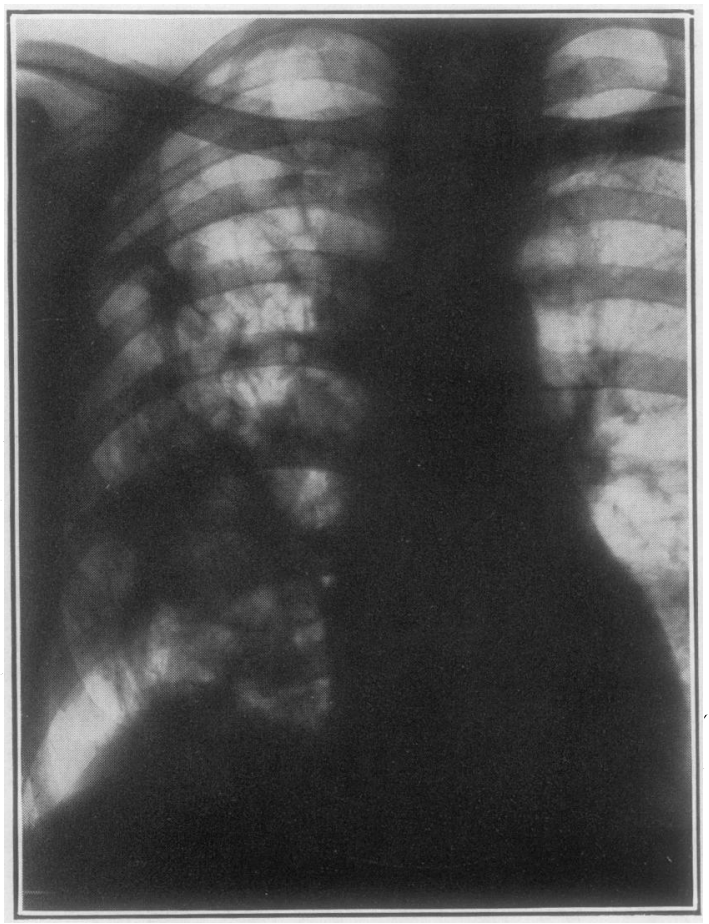

Fig. 7.-Case 5, Sept. 30, 1943. On admission, three months later; there is extensive fibrotic lesion in all zones of the right lung, with thinwalled cystic appearance in the upper and mid zones, and some consolidation towards the base.

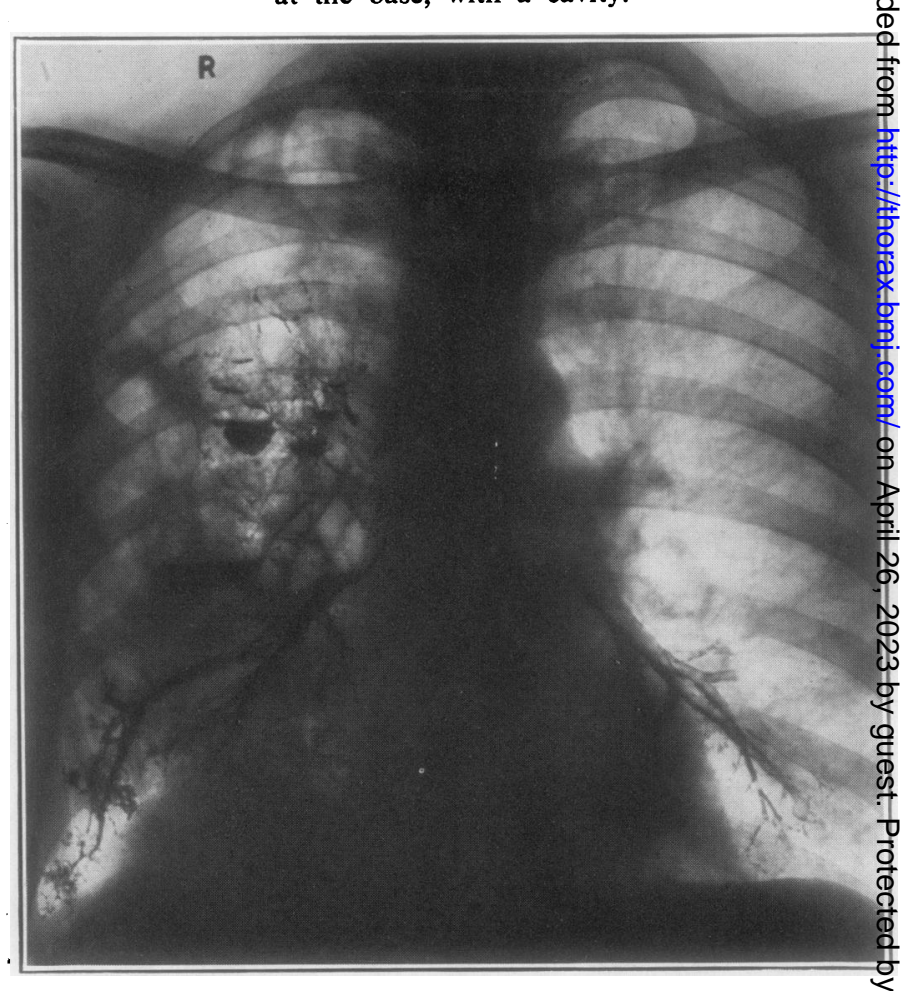

Fig. 8.-Case 5, Oct. 14, 1943. Bronchogram shows extensive cystic bronchiectasis in the right upper and mid zones, an\& also cystic areas situated in the upper lobe anteriorly. 
found in other forms of abscess. In 17 cases the right lung was involved, in 6 the left ; in 15 the lesion originated in the upper lobe, in 2 in the middle, and in 6 in the lower; in 6 it originated anteriorly, in 3 at the extreme apex, and in 14 posteriorly. The fact that in 9 cases the earliest lesion arose in areas where acute putrid abscess is rarely found suggested that inhalation of infected material was not the cause of the pathological changes.

The subsequent behaviour of the lesions, as seen in the radiographs and on the screen, was diagnostic. All showed direct extension of the consolidation to immediately adjoining areas. Accompanying this extension some degree of resolution took place in the area first involved, and sometimes the cavities disappeared. The new areas often showed cavitation in their turn, sometimes transient, often persistent. The creeping spread of the consolidation and cavitation was the most noticeable and characteristic phenomenon, and in a large proportion of the cases the whole lung was involved at some period of the disease. Extension to the opposite lung occurred only in one case, and then as a terminal event. This type of spread contrasts with that seen in the adult or re-infection type of pulmonary tuberculosis. In tuberculosis a new shadow or group of shadows appears at a variable distance from the original lesion. The spread in suppurative pneumonitis, however, appears as an actual increase in size of the original shadow. The lesion in pulmonary tuberculosis is nearly always shown as a characteristic mottling, which is so constant that it may be regarded as the basic picture of this type of tuberculosis. In suppurative pneumonitis this mottling was not present.

To the radiologist it appeared that the spread of the process was due to direct infiltration of the lung and not to a bronchogenic spread. It has already been mentioned that cavities which occurred during the active phase of suppurative pneumonitis were either transient or persistent. In the temporary form of cavity a translucent area with smooth walls suggested a considerable element of distension, while in the more persistent type the wall was irregular with a serpiginous outline suggesting actual necrosis of the lung. In this latter type the bronchus or bronchi leading to the cavity were usually patent ; this was demonstrated in one instance by introducing a fine tube into the cavity followed by its passage first into the bronchus and finally into the trachea. Study of the radiographs of these cases showed that when the active phase of the disease has subsided, as shown by resolution of the consolidation, considerable lung damage may have resulted. Of the 23 cases analysed, in 14 the final radiographs showed changes which were probably due to fibrosis and bronchiectasis, though proof by bronchography was not obtained in all of them. Bronchograms when performed in cases of this group showed bronchiectatic changes either of cylindrical or saccular form. Eleven cases showed persistence of cavitation in the last available radiograph, and only 2 showed resolution to a comparatively normal lung. One case is still in the active phase of the disease, and 4 cases died in this phase. Two 
cases (case reports 5 and 6) are of particular interest in that bronchography in the early stages of the illness showed a comparatively normal bronchial tree except for some lack of filling in the small areas originally involved. Subsequent bronchography, in one instance one year, and in the other five years later, revealed extensive bronchial dilatation and thin-walled cavities in the lung. There is thus proof of the development not only of bronchiectasis but of actual cavity formation ; these cavities may show multiple bronchial communications.

To summarize, all the cases examined showed certain characteristic radiological appearances and progress. Early consolidation was succeeded by softening; later there was direct extension of the lesion, frequently associated with resolution in the areas previously involved. The majority of cases showed permanent lung damage in the form of bronchiectasis and persistent cavitation.

\section{Clinical Course}

The onset of suppurative pneumonitis is variable and its course is unpredictable. The majority of our cases presented a clinical picture which was sufficiently constant to permit a standard description. Of the 27 cases, 25 occurred in adult males. Their ages ranged from 31 to 55 years, with the exception of one patient who was 20 and a second who was 62 . The average age was 46.5 years. In 14 patients the onset was insidious, with malaise, cough, slight mucoid sputum lasting two or three weeks, and symptoms which suggested a cold or a mild attack of influenza. In 13 the onset was acute, but a proportion of these patients confessed to a mild catarrhal condition preceding and overshadowed by the more dramatic symptoms which followed. Apart from the fairly constant history of a prodromal catarrhal infection, a proportion had a pre-existing condition which might have had some bearing on the onset. Thus, 4 cases occurred after an operation (including one dental extraction); in 2 cases there had been a preexisting bronchitis, and in 1 a history of malaria. Three patients were submitted to severe exposure before the onset of suppurative pneumonitis. In 7 there was gross oral sepsis, and in 3 cases sinus infection. The patients came under observation after intervals varying from $1 \frac{1}{2}$ weeks to 5 years from the onset of symptoms. Excluding one whose history was five years, the average interval was 6 months. They have been under observation for periods varying from one month to $2 \frac{1}{2}$ years, with an average of 13 months.

Most of the patients were males of middle age. They complained of sudden onset of severe cough and copious sputum, frequently accompanied by sweating, prostration, and pain in the chest. Temperature, on admission to hospital, varied from normal to $103^{\circ} \mathrm{F}$., with a typical range in the acute phase from $100^{\circ}-101^{\circ} \mathrm{F}$. Nineteen patients complained of dyspnoea. Haemoptysis occurred during the course of the illness in 19, but in 4 of these it consisted of staining of the sputum only. The general condition was classified as good in 7 patients, fair in 14, and 
poor in 6. Physical signs varied according to the phase of the disease. In the acute phase the signs were those of bronchopneumonia, but in some there were extensive areas of consolidation. As time passed the physical signs often became equivocal, even in the presence of extensive cavitation and copious sputum. Clubbing was present in 14 patients. At the onset of the acute illness the sputum changed from mucoid to frankly purulent material, and ranged in quantity in different patients from $2 \mathrm{oz}$. to $30 \mathrm{oz}$. each day. Patients frequently complained that the sputum had an unpleasant taste and odour, even when other people could not detect anything more than a faintly sour smell. But the sputum of 14 patients was definitely foetid on admission, and in 9 others there was foetor on some occasion during the course of the illness. In 6 only was the sputum non-foetid throughout.

No organisms which could be regarded as of aetiological significance could be found in the sputum. Cases in which a constantly predominating organism could be demonstrated (e.g., pneumococci, staphylococci) have been excluded from this series. They responded to sulphonamides or penicillin, and they differed in clinical course from those under discussion. Anaerobic organisms. moulds, and yeasts were not found ; but there were few observations made on the sputum bacteriology during the presence of foetor. Nine cases had a white cell count of more than 12,000 per $100 \mathrm{c} . \mathrm{mm}$. of blood, the maximum recorded being 17,$000 ; 6$ had a haemoglobin percentage of less than 70 , and the sedimentation rates varied between 35 and 60 (Westergren, 1 hour) in the acute phase.

The course of the illness was characterized by remissions and relapses. During periods of remission the general condition improved, the sputum decreased markedly, and some resolution of the lesions was seen radiologically. Relapses, which occurred in a period of weeks or months, were accompanied by a return of symptoms and an extension of radiographic shadows. Toxaemia, in the acute stage or in relapses, was often severe and resulted in the death of 6 of our patients. Empyema as a complication did not occur, but there were two cerebral abscesses, one of these being after operation.

\section{Pathology}

The pathological material available for study was derived from those cases which died (10 cases, with 6 autopsies); and some severe cases which required pneumonectomy ( 3 cases). The morbid anatomical descriptions of the lungs in these advanced cases are given with the clinical reports. The lungs were characterized by extensive adhesions, thickening of septa, areas of emphysema, collapse and pneumonitis, multiple abscess cavities, and enlargement of lymph glands. There was nothing specific about the histology of the abscess cavities, and the associated changes were such as might be found in any lung with chronic sepsis. The cavities varied in size. The smaller were often situated in the depths 


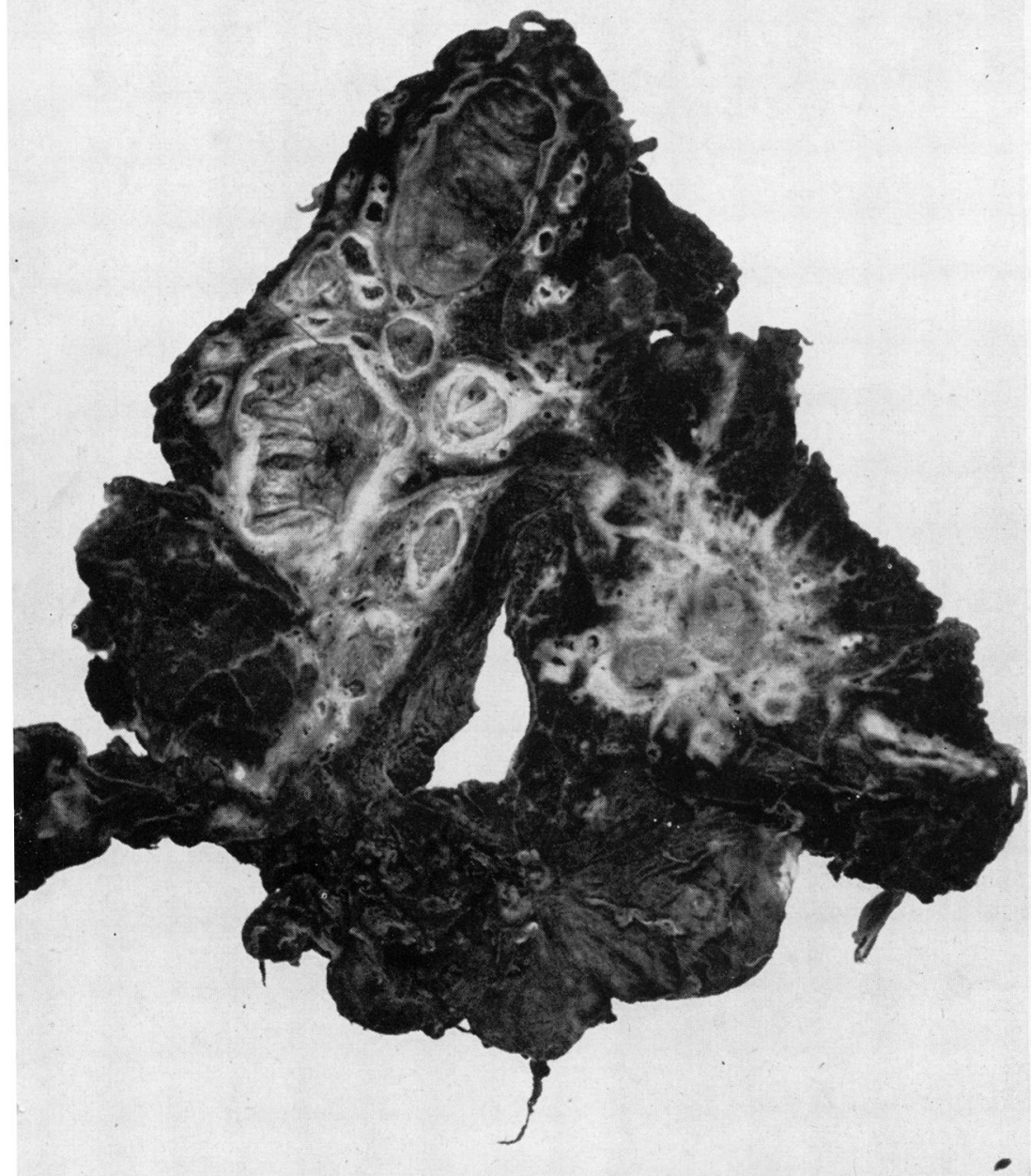

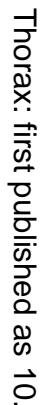

FIG. 12.-Case 5. Cavities in upper and middle lobes with respiratory epir thelial lining. Fibrosed bulla apex. Chronic abscess with squan, ous lining in lower lobe.

FIG. 13-Case 5. Ciliated epithelium oi scar tissue base with ring of squamo ous metaplasia about a persisten point of ulceration (corresponding to the darkest spot in large cavity of Fig. 12).

Fio. 12.

Fig. 13

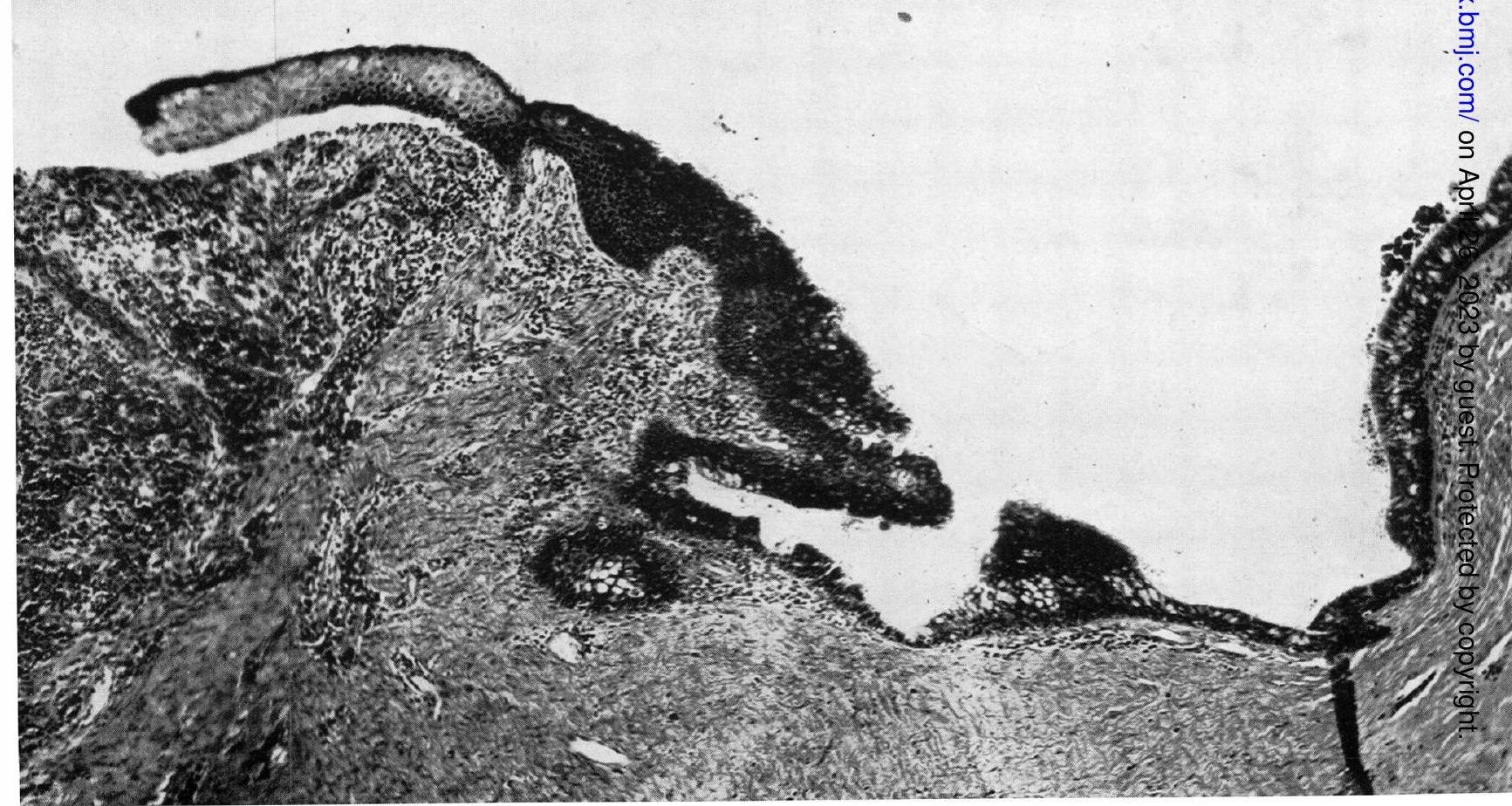


4.7. 3 .

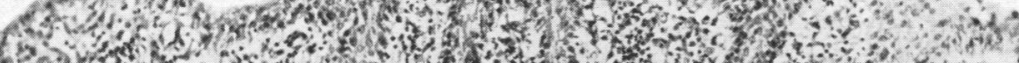

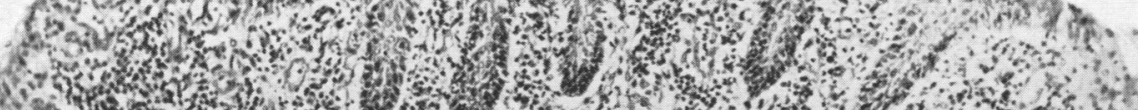

2. 1

(3)

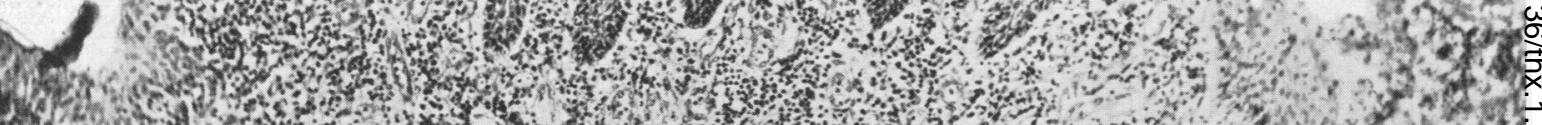
Mp

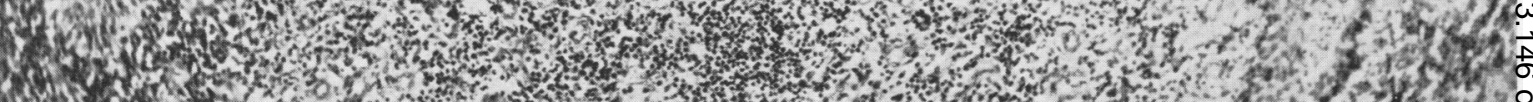

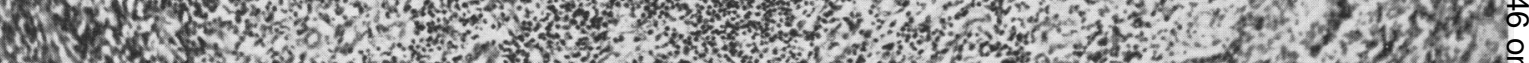

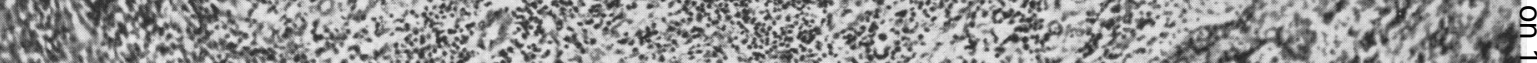

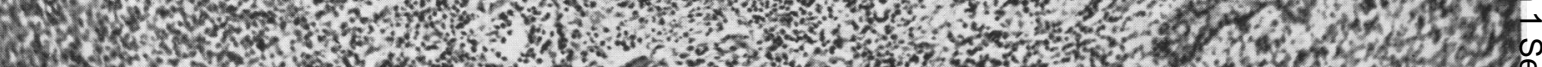

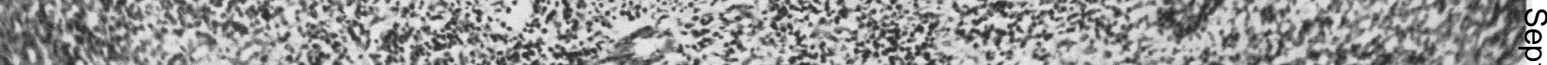

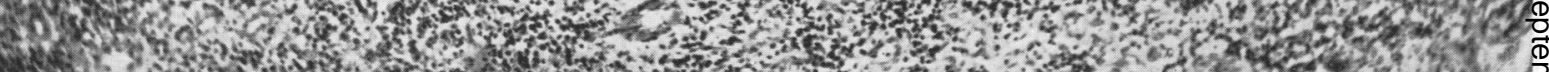

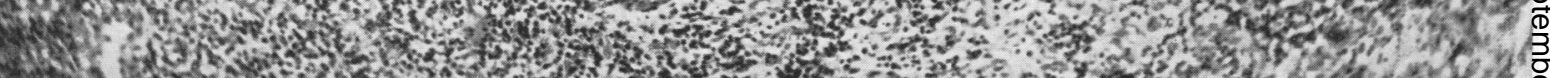

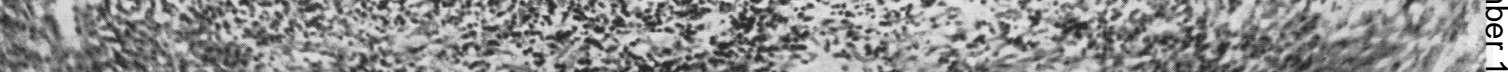

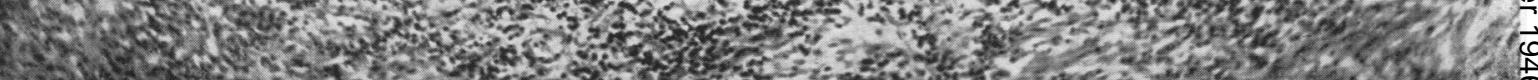

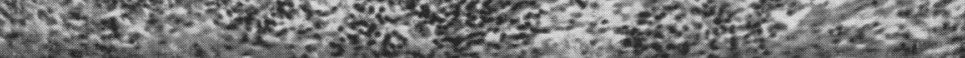

FIG. 14.- Squamous epithelium lining chronic basal abscess in Case $5(\times 100)$.

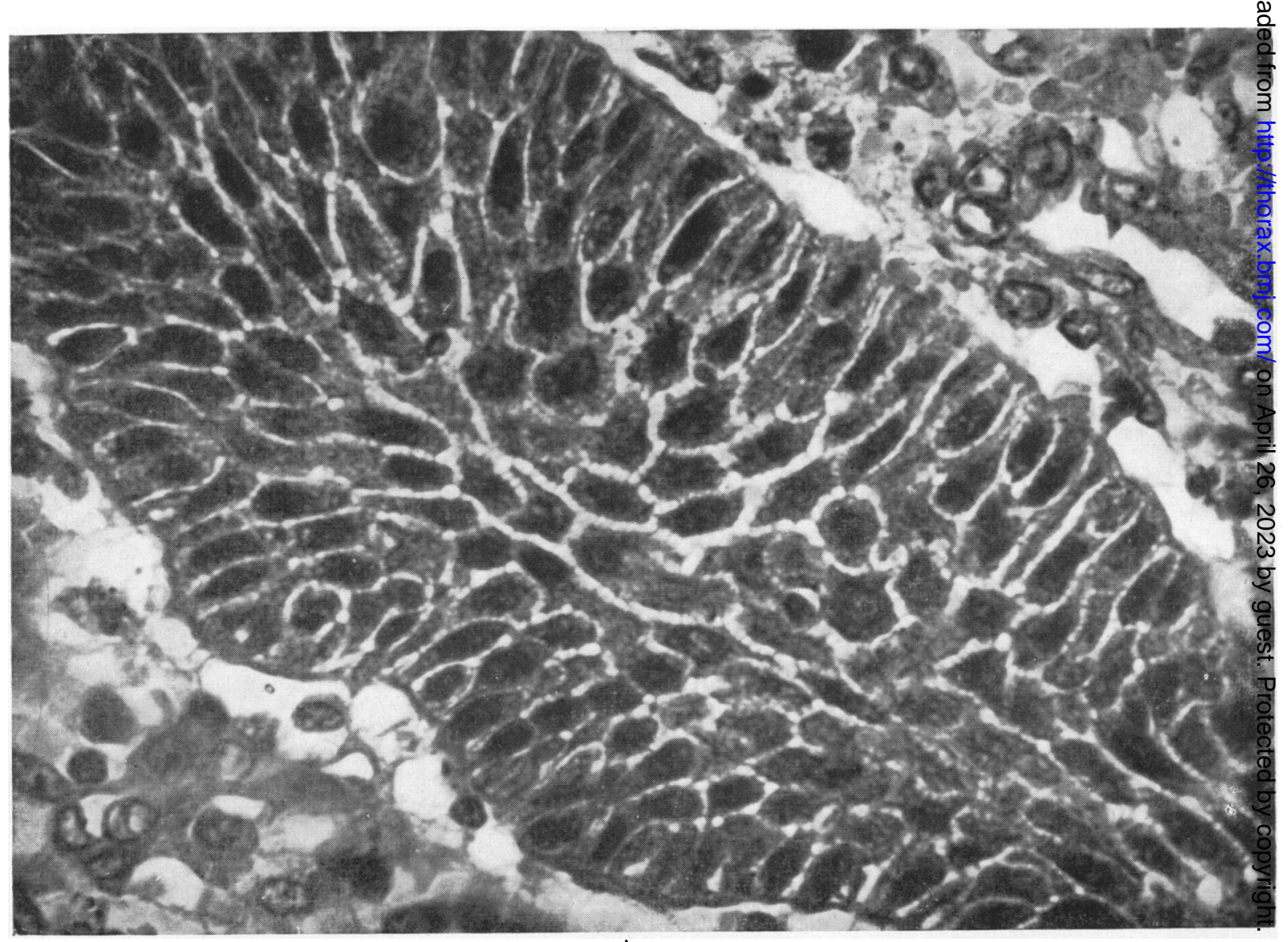


of the lung, whilst the larger tended to extend to the periphery. They often had multiple bronchial communications, and sometimes communicated with each other. This feature was most noticeable in the large cavities. In 2 of the pneumonectomy specimens there was a very striking variation in the character of the different cavities in the same lung. Some had a fibrous wall with a granulating pyogenic surface. Others had a complete or partial lining of well differentiated squamous epithelium with prickle cells and rete pegs (see Figs. 14 and 15). Others had a lining of ciliated columnar epithelium superimposed on scar tissue (see Fig. 17). Cavities of recent origin (like that in the anterior part of the middle lobe in Fig. 16) contained a slough rooted proximally where the necrotic bronchi entered. The slough in more chronic cavities (lined with squamous epithelium, like that in the lower lobe in Fig. 12) has disintegrated, the cavity being filled with pus which was mostly amorphous and apparently old. Cavities with respiratory epithelium contained air with a variable amount of muco-pus, and were obviously undergoing ciliary drainage. One of these cavities contained a rounded brownish broncholith which was probably derived from a slough. It had little resemblance to a calcified tuberculous focus.

The cavities originated in the breakdown of pneumonitic lung, whilst their subsequent extension across septa and into multiple bronchi was by ulceration. Radiological findings, however, point to these lesions, like other necrotic lesions in the lung, being subject to variation in size due to air distension. The valvular mechanism producing this is probably the partial block of the communication with the bronchial tree. Air distension may affect both old and recent lesions, large and small. Even minute foci may be affected, bullous distension of such a focus being the explanation of the transient radiological cavities, which appear rapidly, and, with alteration of the mechanics, as rapidly subside. From the pathological point of view cavities with a respiratory epithelial lining are "healed." Although associated with permanent deformity of the normal anatomy, the gross destructive process is arrested and the surface continuity re-established with epithelium of the normal type. They appear to be lesions which have healed quickly on account of good drainage. They probably date from the earliest stages of the disease when conditions were more favourable for healing. Rapid healing in the late stages of advanced and severe cases would be most unlikely. Epithelialization appears to take place not only from the mouths of the proximal bronchi but also from the small peripheral twigs. Respiratory epithelium cannot spread as such. In these cavities it is probably derived from epithelium of a flat or cuboidal type which spreads over the ulcerated surface and later differentiates. This is in line with the work of Montgomery on the healing of lung incisions.

Squamous epithelium appears to have formed where epithelialization was difficult or repeatedly interrupted. The large cavity in Fig. 12 was completely lined by ciliated epithelium except for the small dark spot where a persistent 


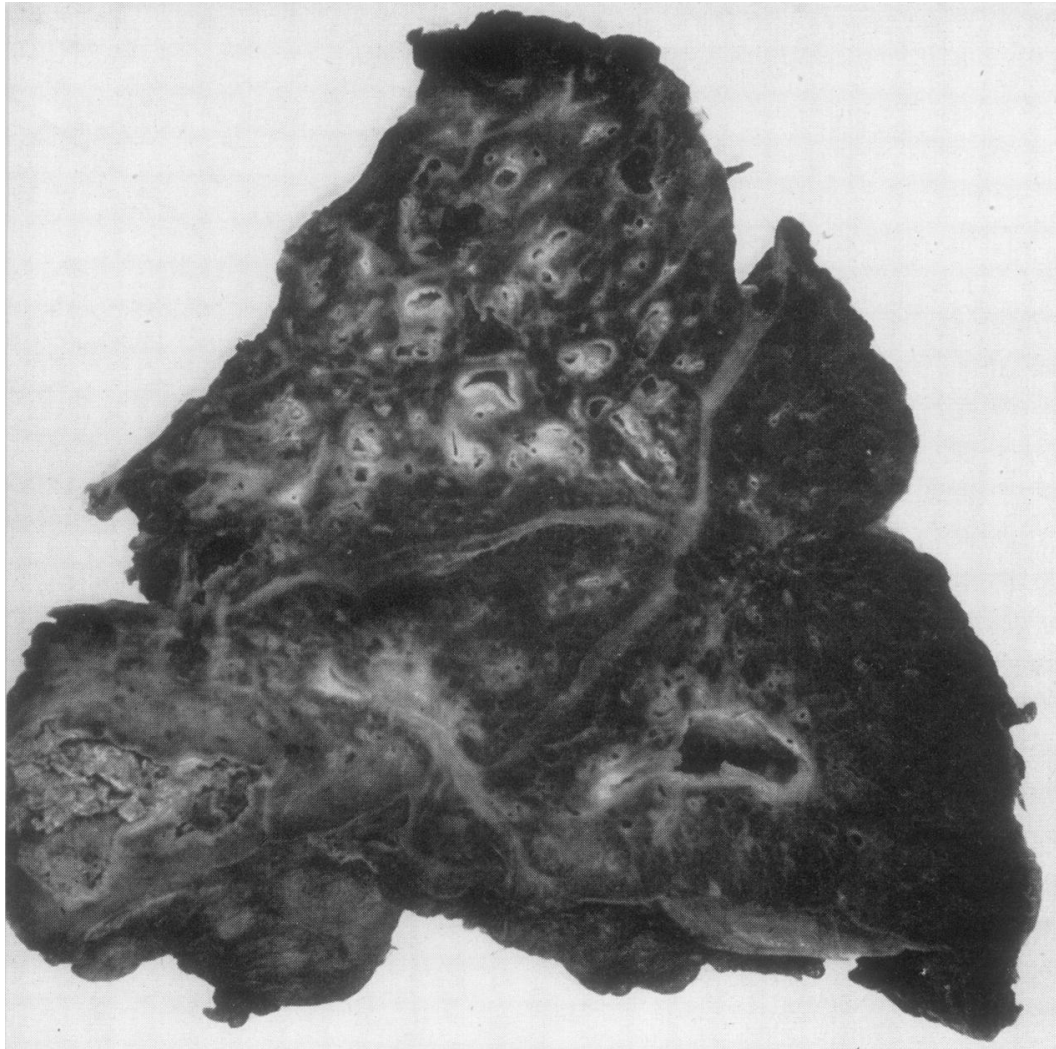

FIG. 16.-Case 6. Upper lobe with co municating healed cavities. Healed cavity in lower lobe, and slit-like c@ lapse of similar cavity in middle lob. Abscesses in anterior parts of upper a d middle lobes (the former ruptured $\mathrm{cm}^{\mathrm{n}}$ excision).

FIG. 17.-Case 6. Respiratory ciliated e $\overrightarrow{\mathrm{PO}}$ thelium superimposed on scar tissue nealed lower lobe cavity $(\times 100)$.

FIG. 16.

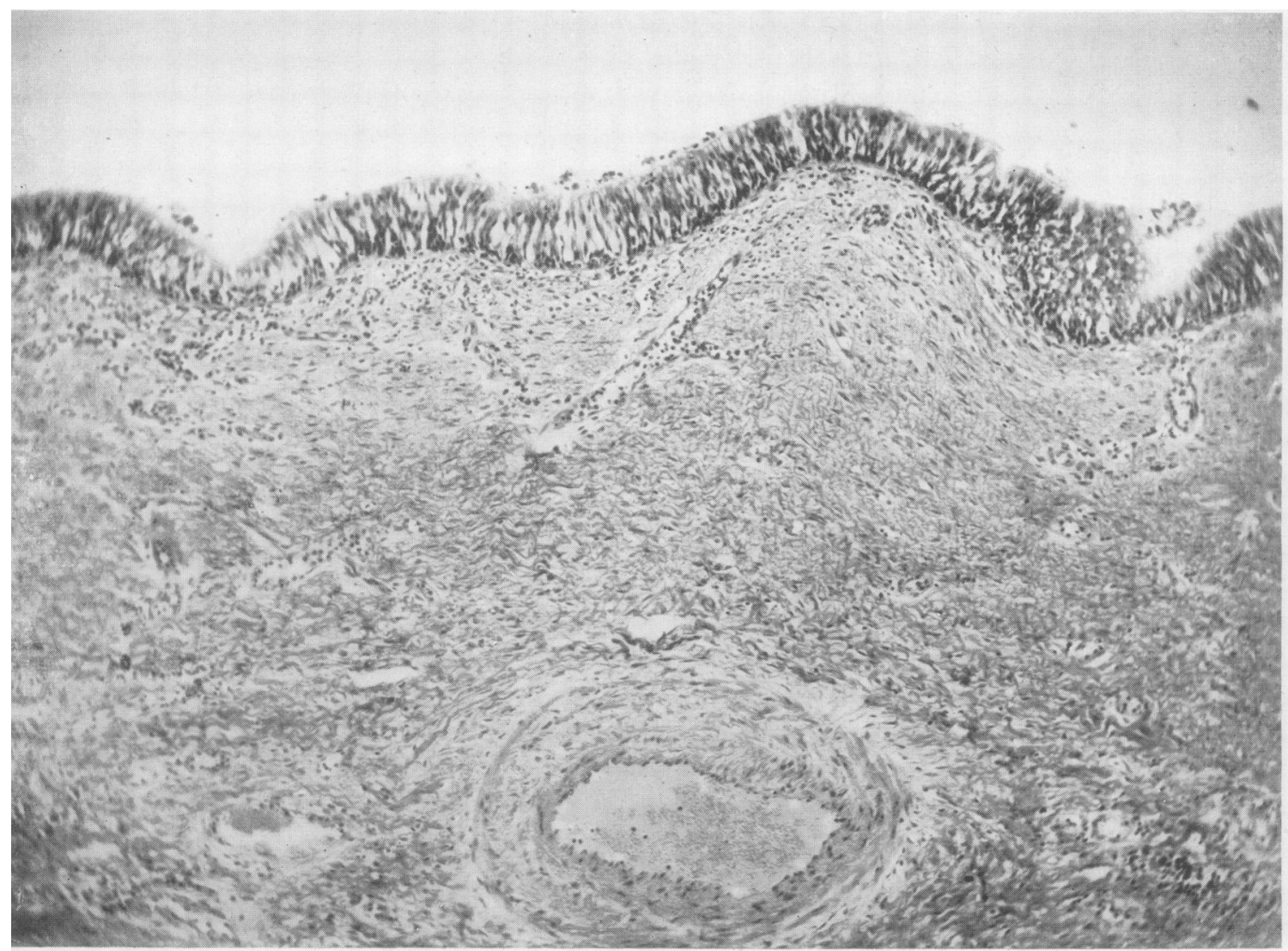

Fig. 17. 
ulcer was ringed with squamous epithelium (Fig. 13). According to Passey et al., squamous metaplasia of respiratory epithelium is one of the changes which results from vitamin A deficiency; in cage bronchiectasis of rats it is generally found in those animals whose diet is deficient in this particular factor. If, as seems probable, vitamin $\mathrm{A}$ is necessary for the maintenance of respiratory epithelium, repeated ulceration with abortive attempts at healing would cause an increased local demand, which, in some cases of partial deficiency, would not adequately be met. In cases with multiple abscesses it seems that these lesions arise in succession. This is especially likely in cases with lesions of different types. The disease is associated with excessive sputum, and this is not only derived in large measure from the cavities, but is occasionally productive of further pneumonitis and possibly cavitation. The aetiological basis of the initial lesion, or lesions, in the present series of cases is not known. The infection may be by the blood stream or by the air passages, and from the present viewpoint the matter is unimportant. It is probable that a necrotic lesion is established, which usually heals but still remains a locus minoris resistentiae, and which may in some cases give rise to later lesions of a similar nature. The virulence of the infection and the resistance of the patient are obviously of importance in this connexion.

In spite of the excessive sputum, bronchiectasis is not a prominent feature. In Case 6 (Fig. 16) the basal bronchi which communicated with the large healed cavity showed very little change. In Fig. 12 (Case 5) it can be seen that bronchi near the basal abscess show marked chronic inflammation, whilst some bronchi behind the apical bulla are dilated. In Case 2 (Fig. 9) there was marked lingular bronchiectasis. The bronchiectasis was acquired whilst the patients were under observation. The pneumonitis often seen in bronchiectasis, however, sometimes undergoes necrosis, and occasionally in such cases one even encounters "spreading suppurative pneumonitis."

\section{Review of the Literature and Suggested Classification of Pulmonary SUPPURATIONS}

It is apparent that there is at present no satisfactory basis of classification for the various types of lung suppuration which have been described in the literature. A clear-cut description of a disease entity is difficult, not only because of the absence of a known aetiology, but also in view of the unpredictable behaviour of lesions which may appear initially to be similar both clinically and radiologically.

Some writers have regarded lung suppuration of the type described by us as part of the process of evolution of a lung abscess, whereas others have regarded abscess formation as secondary or incidental to the inflammatory process. A lung abscess is defined by Barrett (1944) as "any collection of pus in the lung," and suppurative pneumonitis with cavity formation could, by this standard, be considered as a specialized form of lung abscess. Touroff and Neuhof (1941) 
group a wide variety of suppurative lung conditions under the headings, " acute putrid and non-putrid lung abscess." The essential differentiation between the two main groups depends clinically upon the presence or absence of foetid odour in the breath or sputum, although in a more recent paper Stats and Neuhof (1945) state that, owing to complete bronchial occlusion, foul sputum does not appear, or comes later, in 5\% of cases of putrid lung abscess. Another difference between putrid and non-putrid lung abscess, according to Neuhof and Touroff, is that in the great majority of cases the former is localized to one part of the lung, whereas in the non-putrid abscess the "bronchopneumonic process may involve various parts of the lung and often the opposite lung concomitantly or in sequence. These additional areas may also undergo cavitation completely, partially or not at all, thus producing multiple cavities or various combinations of cavity formation and pneumonitis." The same authors (1938) have ascribed the development of non-putrid lung abscess to a pre-existing necro-suppurative bronchopneumonia which they define under the following headings:

(1) Pathologically: the co-existence of suppuration and necrosis involving one or more broncho-pulmonary segments ;

(2) Clinically: recurrence of fever and the expectoration of odourless pus ;

(3) Radiologically: the presence of one or more areas of pneumonic infiltration ; and

(4) Bacteriologically: the presence of aerobic pus-producing bacteria in the sputum.

They tend to regard these changes merely as a prodromal stage in the production of a special type of pulmonary abscess ; transformation into an abscess may take place rapidly or gradually, and they consider that "a transitional stage undoubtedly exists."

A rather different emphasis has been placed upon the pathology of pulmonary suppuration by other writers, particularly in this country. Barrett (1944) agrees with Scadding that non-putrid abscess formation is only an incident in the course of a peculiar type of bronchopneumonia, and that as such its presence is relatively unimportant. He thinks that non-foetid abscess is the same condition as described by Scadding (1936 and 1938) as chronic suppurative pneumonia with abscess formation. Scadding (1936) reports three cases of chronic pneumonia simulating pulmonary tuberculosis clinically and radiologically, which proceeded to a fatal termination in periods varying from $3 \frac{1}{2}$ months to 2 years. In a later paper (1938) he describes 8 cases of chronic pneumonia under the following headings:

(1) Chronic circumscribed non-suppurative pneumonia ;

(2) Chronic suppurative pneumonia ; and

(3) Chronic suppurative pneumonia with abscess formation. 
In the first type suppuration is probably only an insignificant feature; the second and third types have many features in common with the series presented in this paper. Donaldson (1944) describes a case of non-odoriferous chronic lung abscess with spreading characteristics that simulated pulmonary tuberculosis. The lung was ultimately removed and was found to have "infiltration and cavitation throughout." The cavities were "flaccid and slightly beefy" in appearance with no special lining. No significant organisms could be recovered. A preliminary account of the clinical and radiological features of suppurative pneumonitis based on some of the material which is included in the present series has been given by Houghton (1944) and Blair (1944).

Reference should also be made to certain lung suppurations of specific aetiology. Friedländer's bacillus pneumonia, described by Collins and Kornblum (1929) and by Belk (1926) may simulate pulmonary tuberculosis or suppurative pneumonitis. Staphylococcal pneumonia described by Heffron (1939), and occurring chiefly during influenzal epidemics, may show cavities which are said to be secondary to bronchial inflammation. The typical staphylococcal pyaemic or septicaemic abscess produces a picture which is unlike the suppuration considered in this article. Kessel (1930) has described non-putrid pulmonary necrosis - which is in fact a residual abscess-following pneumococcal pneumonia, giving no symptoms, and clearing rapidly and spontaneously.

The cases described by us as "spreading suppurative pneumonitis" do not completely coincide with the records of other writers, although our cases have much in common with those described by Scadding as chronic suppurative pneumonia with cavitation, and by Neuhof and Touroff as non-putrid lung abscess. We feel that there has been considerable difficulty in defining the term "lung abscess" and we believe that the differentiation of abscesses into putrid and non-putrid is not valid. In all but six of our cases the sputum was foetid at some time during the illness, though admittedly this was by no means a constant feature. Fcetor of the breath and sputum depends upon the presence of anaerobic infection and retained necrotic tissue, and is conditioned by bronchial drainage. It can, therefore, occur in any cavitation in which these conditions are fulfilled, and is not necessarily a diagnostic characteristic.

\section{Suggested Classification of Lung Abscesses}

Cavities can develop as the result of (1) a pneumonic process, (2) bronchial obstruction, and (3) vascular embolism.

1.-Pneumonic abscesses are divided into:

(a) Specific forms. This large group includes cavities resulting from tuberculosis, staphylococcal, and other forms of infection in which some constant and dominant organism can be isolated. 
(b) Non-specific forms. In these no definite cause can be established, and "spreading suppurative pneumonitis with cavitation" is regarded as an example of this form.

2.-Abscesses due to bronchial obstruction are divided as follows:

(a) Sub-lobar. This is the condition that is usually designated as acute putrid lung abscess occasioned by inhalation of infected matter which becomes lodged in a bronchus and initiates peripheral necrosis. Distribution follows the sub-lobar sectors of the lung, and leads to an abscess presenting on the periphery. Anaerobic infection in these cases is almost constant, and accounts for the foetor. The abscess is usually single.

(b) Lobar. This form occurs as a result of lobar collapse, as may be seen post-operatively. The abscesses formed are usually multiple.

\section{3.-Embolic abscesses.}

These arise from infection carried from other parts of the body into the lungs. They can either be single or multiple; if the latter, they may be scattered in any part of the lungs. A single large area of necrosis may occur as the result of dislodging, for example, a femoral thrombosis.

\section{DifFERENTIAL DiAgNOSIS}

Suppurative pneumonitis is frequently confused with other conditions, notably obstructive and embolic lung abscesses, pulmonary tuberculosis, and neoplasm. There are also a number of less common conditions which occasion diagnostic difficulty; these include bronchiectasis with added pneumonitis, infected cysts, specific forms of pneumonitis, actinomycosis, and adenomatosis of the lung.

Obstructive Lung Abscess.-The classical acute lung abscess has an essentially dramatic onset with severe initial toxaemia, and at the same time the breath is offensive even before sputum is produced. There is often a history of some foreign material having been inhaled, or at any rate there is the possibility of this having occurred. A recent operation with anaesthetic difficulty, or operations on the upper respiratory tract, may suggest an origin for the obstruction; but in the absence of operation there may be marked dental, oral, or sinus sepsis. Radiological distinction at the first examination may be difficult, since suppurative pneumonitis may start at the sites of election of obstructive abscesses (e.g., the dorsal part or apex of the lower lobe, and the postero-lateral or scapular segment of the upper). In suppurative pneumonitis the appearances of consolidation overshadow those of excavation, whereas in obstructive abscess the cavitation is the striking feature and occurs at a much earlier stage. The subsequent behaviour of the lesions is also different, in that extension-should it occur in an obstructive 
abscess - is usually seen as the development of a fresh segmental abscess and does not show the extraordinary creeping of the lesion already referred to as typical of suppurative pneumonitis.

Embolic Lung Abscess.-This form of abscess usually appears in disseminated patches of consolidation which change rapidly in size. When cavities form they have thinner walls than are seen in the obstructive form and are characteristic of distension. As the definition implies, there is evidence of sepsis elsewhere.

Pulmonary Tuberculosis.-Suppurative pneumonitis has many points in common with pulmonary tuberculosis. Both diseases may follow a similar course and may lead to cavitation with the production of sputum. Radiologically the lesions have also much in common ; but the mottling so typical of tuberculosis is not seen in suppurative pneumonitis. There are also points of difference in the method of spread and in resolution. Extension in tuberculosis does not show the creeping characters of spreading suppurative pneumonitis; and, if the tuberculous lesion is at all extensive, it is very uncommon to find that the opposite lung remains normal. When resolution occurs it is generally more rapid and complete in suppurative pneumonitis than in tuberculosis. In suppurative pneumonitis there is at some stage of the disease offensive or foetid sputum which is not found in uncomplicated tuberculosis. Furthermore, the repeated absence of tubercle bacilli from the sputum, in the presence of an extensive radiological lesion and copious purulent sputum, strongly suggests that the condition is not tuberculous. It must be mentioned, however, that the occasional recognition of tubercle bacilli in the sputum does not inevitably exclude suppurative pneumonitis, since the inflammatory process may in its course liberate encapsuled bacilli if a quiescent or healed tuberculous lesion becomes involved. The clinical course of the two conditions can be remarkably similar.

Carcinoma of the Lung.-Suppurative pneumonitis often simulates some forms of carcinoma of the lung, and difficulty may arise in those cases in which bronchoscopy is negative. There are two forms of carcinoma which can cause diagnostic difficulty: the first is the peripheral breaking-down growth. This usually appears in a radiograph as a rounded opacity containing a cavity with irregular walls. The position of the cavity in relation to the opacity is variable, and may be eccentric or central. There is no tendency for rapid spread of the lesion apart from slow increase in size due to the actual extension of the growth. The sputum is not usually foetid, and may contain malignant cells. The other form of carcinoma consists of breaking down of lung tissue distal to a bronchial growth which has produced obstruction. This closely resembles the obstructive form of lung abscess and may be similar in its segmental distribution. The sputum is not generally foul, and the lesion does not actively spread, though, if the growth involves an adjacent bronchus, it may produce a fresh area of atelectasis which suggests the spread of an inflammatory process. The possibility of 
confusion with carcinoma makes it imperative that all suspected cases be bronchoscoped without delay and in the event of negative findings this investigation should be repeated.

Bronchiectasis.--There are certain similarities between suppurative pneumonitis and bronchiectasis in which there has been an added pneumonitis. The bronchiectatic lesion, however, tends to clear quickly and may not cavitate. It should be possible to elicit a previous history of cough with purulent sputum which has been present for a long period, and the presence of established dilatations on bronchography should leave little doubt as to the diagnosis.

Infected Cysts.-Cysts within the lung are usually very thin-walled, and even though they become infected there is not much surrounding consolidation. Fluid levels are commonly seen once infection has become established. The onset of infection in a cyst is usually acute, though on occasions it is insidious and is characterized by low-grade toxaemia with the gradual development of cough and sputum.

Specific Forms of Pneumonitis.-Most of the specific types of pneumonitis with cavitation are disseminate, though they may closely resemble suppurative pneumonitis, both clinically and radiologically. The diagnosis of these forms is determined by the constant finding of a definite organism in the sputum. Examples of this are infections produced by Friedländer's bacillus and staphylococci, and atypical forms of pneumococcal pneumonia. It should be noted that staphylococcal lesions may produce enormous abscesses of the distension type which may be mistaken for cysts.

Actinomycosis.-Actinomycosis may affect the chest in a variety of ways. It may appear as a relatively localized lesion, but frequently tends to invade the pleura and chest wall. There are no particular radiological or clinical characteristics of this condition, and the diagnosis can only be established by the finding of the streptothrix in the sputum.

Adenomatosis.-Adenomatosis is a spreading malignant condition in the lung, probably arising at the terminal bronchioles. It is a rare condition, and, if encountered, may give considerable difficulty in diagnosis, as the radiological picture is that of spreading consolidation very similar to the spread in suppurative pneumonitis. There is, however, not the same tendency to cavity formation. Sputum in adenomatosis also may be very large in amount, but it has not the purulent characteristics of that found in suppurative pneumonitis.

\section{Prognosis}

The outlook for a patient with spreading suppurative pneumonitis is not good. At best he is faced with a long illness; the average duration of symptoms before admission to the Chest Unit was $8 \frac{1}{2}$ months in our patients. The prospect of 
cure by conservative measures is less than $20 \%$. In the series of 27 patients under review, 10 died ; 8 improved but were left with residual symptoms such as cough and sputum, and these still show radiological evidence of fibrosis, bronchiectasis, or cavitation: though afebrile and able to undertake light work, they are liable to exacerbations, and the end results cannot be considered satisfactory. In only 5 instances did the condition resolve as a result of conservative treatment, and these patients are now well and free from symptoms, although in 3 some radiological evidence of the old lesion still remains. In 4 patients a satisfactory outcome was obtained by radical pulmonary resection. It is significant that of the 5 patients in whom resolution occurred, 4 had a history of less than 8 weeks' duration, the other of 4 months'. The prospects of cure by conservative measures are poor if the condition has been in existence without improvement for more than 2 months. By that time irremediable damage has been done to the lung, and, even if the progress of the disease is arrested, the persistence of some permanent symptoms must be expected.

\section{TREATMENT}

Our experience has now enabled us to form fairly definite opinions as to the treatment of the condition. Not all the patients in this series received the treatment that we now advocate. This is partly because at the beginning of the period under review we lacked knowledge of the condition, and partly because during these five years advances in operative and anaesthetic technique have made pulmonary resection a much safer and more successful procedure. The introduction of penicillin has offered the prospect of better results in the treatment of pulmonary inflammation, not only as an agent in conservative measures, but also as a definite technical aid to the surgeon.

There are many methods of treatment that may be applied to these patients ; most of them have been tried and require some comment.

General Measures.-Patients suffering from spreading suppurative pneumonitis should be admitted to an institution where full facilities are available for their proper investigation and treatment, and where there is no undue pressure on beds, so that if necessary they may remain for months. In some respects the requirements are similar to those of a pulmonary tuberculosis institution. Bed rest is clearly indicated during the acute and febrile stages; and, as improvement occurs, exercise should be graded slowly so that the patient experiences no fatigue. The diet must be liberal and tempting; the patient should be encouraged to eat as much as he will, and when the sputum is copious, protein intake should be generous. Expectorant mixtures, and drugs to promote rest, appetite, and relief of pain, all have their place in treatment but no specific effect on the progress of the disease. The presence of anaemia demands the administration of iron and often transfusion of blood. We have found the latter a valuable 
measure, not only in the acute stages when anaemia was of a severe and progressive nature, but also before and during operation.

Chemotherapy.-Drugs of the sulphonamide group were administered to all our patients at some time or other ; they were often given in repeated courses, but the results were disappointing. It was frequently observed that some improvement occurred during the actual administration of the drug, but the patient's condition relapsed when the course ended. We were unable to attribute any lasting beneficial results to the sulphonamides.

Penicillin was not available for the majority of the patients, and only 8 received this treatment. The impression gained was that during the acute phase of the disease its effect was better than that of the sulphonamides, but, as with the latter, the improvement was not maintained after the administration ceased; it has, however, an advantage over the sulphonamides in that it can be administered for long periods without harm. In chronic cases in which the patient was afebrile but had infected cavities and bronchiectasis, penicillin appeared to have no effect. It has been given systemically, and by inhalation from a Collinson's inhaler. We have found that an adequate blood concentration can be obtained by the latter method, but the cases in this group are too few to allow any conclusions to be drawn about the relative efficacy of the two methods of administration.

Bronchoscopy.-All the patients in this group were bronchoscoped. This was done more as a method of investigation than for purposes of treatment. It is an essential aid to diagnosis, especially to exclude carcinoma of the bronchus or bronchial obstruction from other causes. As a therapeutic measure bronchoscopy has little value, though some patients have stated that it alleviated their symptoms, and under such circumstances it is worth repeating.

Physiotherapy.-Treatment by a physiotherapist trained in the management of chest disease can be a great advantage during the whole course of the illness. In the acute stage breathing exercises are contra-indicated, but postural drainage based on a careful examination of the posture required is to be encouraged and applied by the physiotherapist. At a later stage breathing exercises should be employed to improve pulmonary function.

Cavity Drainage.-It has been realized for many years that certain lung abscesses should be drained and others should not, but no general agreement has been reached as to which should be drained or when. In this series drainage operations were consistent failures; before admission 3 patients had had ineffectual operations for drainage; after admission an attempt to drain the cavity in 2 patients failed, and the only 3 who had effectively drained cavities died -2 from general deterioration and 1 from secondary haemorrhage. Radiographs of the lesion, together with examination of autopsy and operation specimens, lends support to our clinical experience that it is wrong to attempt to drain the 
cavities in this condition. Failure to find the cavities at operation is explained by their occasional transitory nature and by their depth in the lung; and failure to achieve any clinical benefit when they are drained is explained by the fact that they are usually multiple and frequently epithelialized.

Collapse Therapy.-Although certain similarities of suppurative pneumonitis to pulmonary tuberculosis suggest treatment by collapse methods, we have considered such methods inadvisable. Artificial pneumothorax in the acute stage would carry a heavy risk of empyema, and in the chronic stage would be impractical on account of pulmonary adhesions.

Pneumonectomy and Lobectomy.-Radical excision of a lung or lobe may be the only method of saving the life of certain patients; in others, whose life is not in immediate danger, it may be the only method of dealing with the lesion. The tendency of the disease to spread across the fissures makes it necessary in most cases to remove the whole lung. In this series 5 pneumonectomies and 2 lobectomies were performed ; there were 3 operative deaths, 1 from air embolism, 1 from cerebral abscess, and 1 from operative shock. Although these figures do not suggest that radical pulmonary resection is a safe procedure, we have come to the conclusion that it is the best method of treatment in certain cases, and recent advances and experience lead us to believe that better results may be expected in the future.

There are two distinct stages of the disease at which operation should be undertaken. During the acute stage, when the patient's condition is deteriorating and the lesion continues to spread, the surgeon may come to the conclusion that the patient will die unless his lung be removed. Under these circumstances we recommend that every effort should be made, by blood transfusion, chemotherapy, and postural drainage, to bring about some temporary improvement, and that at the peak of this improvement pneumonectomy should be performed as an emergency operation. There are certain advantages in operating at this stage, for although the pleura is adherent, it is not densely so. The adhesions can be fairly easily separated, technical difficulties are not great, and the operation may be performed with expedition. The second stage at which operation may be performed is in the late phase of the disease, when the acute inflammation has subsided but the patient has a bronchiectatic and cavitated lung. At this stage pulmonary resection is carried out not so much to save life as to rid the patient of incapacitating symptoms such as dyspnoea, cough, and copious sputum. It is in these late cases that the greatest technical difficulties are encountered, for the lung is densely adherent to the chest wall. The operation is long and tedious, the patient's cardiovascular system is impaired by prolonged suppuration, and he may be unable to sustain the severe shock which almost inevitably accompanies the operation. Very careful judgment is required in balancing the risks of the operation against the disability caused by the disease. 


\section{Illustrative CASE RePORTS}

Case 1. Chronic type.-A merchant seaman, aged 41, was subjected to exposure in 1943 when the ship in which he served was sunk. In Jan., 1944, he noticed a slight cough with sputum, pyrexia, and left-sided pain, thought to be pleuritic. Two weeks later a radiograph showed left mid-zone opacity with a fluid level. Within a week this area had become more dense, and the fluid level persisted; there was fever up to $102^{\circ} \mathrm{F}$. and a 4 -oz. haemoptysis.

In March, 1944, he was admitted to Harefield Sanatorium with severe cough, purulent sputum which was sometimes offensive, and pain-not of pleuritic type-but no clubbing of the fingers. On March 27, radiograph showed consolidation of the left upper and middle zones, with a cavity (Fig. 18). Pneumococci and streptococci were present in the sputum, but there were no fungi and no tubercle bacilli. The vital capacity was $3,200 \mathrm{c.cm}$. A bronchogram showed little abnormality, and bronchoscopy showed only undue redness of the mucosa.

In May, 1944, there was an attack of acute pyrexia with $15 \mathrm{oz}$. of bloody sputum. During the administration of a course of sulphamezathine, the lesion spread into the apex of the left lower lobe. A full course of penicillin had no effect. For the next four months there was irregular fever and from 5 to $13 \mathrm{oz}$. a day of sputum, although in the latter two months the general condition improved considerably. On May 19 a radiograph showed that the original cavity persisted, and that a fresh cavity had formed just below, with extension of the lesion downwards into the dorsal lobe (Fig. 19).

In Nov., 1944, the patient, feeling perfectly fit apart from cough and sputum, was discharged having gained over a stone in weight. The vital capacity had increased to $3,800 \mathrm{c} . \mathrm{cm}$. He returned to normal activities in spite of persistent cavitation and $3 \mathrm{oz}$. of sputum. Radiograph showed much resolution though with cavities still present (Fig. 20). Later there was further resolution and suspicion of some bronchial dilatation.

Bronchograms.-A bronchogram on July 6, 1944, showed a normal left bronchial tree except for poor filling in the area involved and possibly some slight bronchial dilatation. One year later there was more complete filling of the area originally involved, with some bronchial dilatation in this area and in the lower lobe which had previously been normal.

Jan., 1946.-Two years from the onset the general condition had been maintained with very little sputum but with persistence of radiographic changes.

Comment.-Clinically recovery was complete, but in view of the persistent radiological lesion there must be some uncertainty about this patient's future (Fig. 21).

Case 2. Fulminating symptoms treated by pneumonectomy.-A soldier, aged 41 , in July, 1945, noticed general lassitude and malaise followed by cough and purulent, inoffensive sputum. He was admitted to a military hospital with "acute bronchitis," and was treated with sulphathiazole without effect. In Aug., 1945, he was transferred to another military hospital and treated with penicillin and blood transfusion with only temporary benefit. Cough, fever, and sputum persisted. Radiographs showed consolidation in the left upper lobe with cavitation (Figs. 22 and 23).

In Oct., 1945 (see Fig. 24), he was admitted to Harefield Sanatorium. Pulse rate was 120 with temperature swinging to $103^{\circ} \mathrm{F}$. and respiration rate 28 . There was persistent cough and expectoration with as much as $36 \mathrm{oz}$. of sputum per day. He was dyspnoeic and cyanosed. Haemoglobin was $65 \%$. The urine contained a trace of sugar and albumen. Sputum examination showed pneumococci and staphylococci but no anaerobic organisms. The mediastinum was displaced slightly to the left. The right chest was 


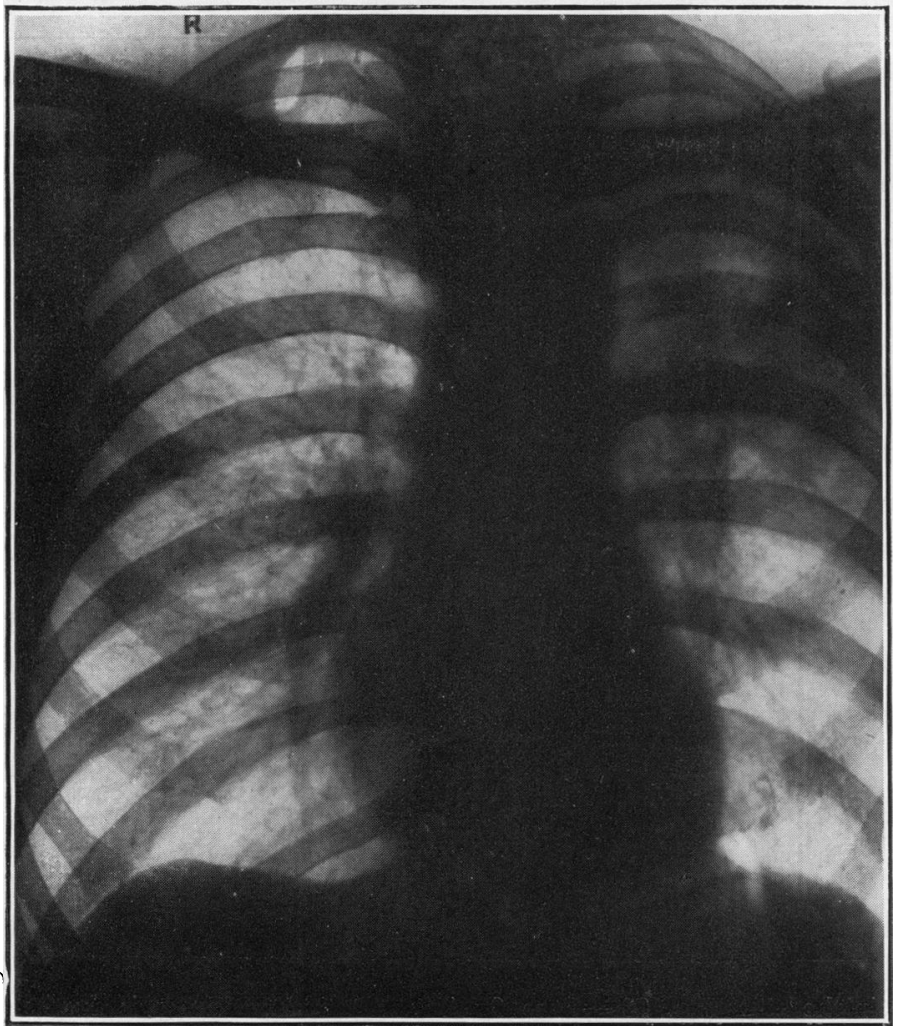

FIG. 18.-Case 1, March 27, 1944. There is partial consolidation of the upper and middle zones with a cavity.

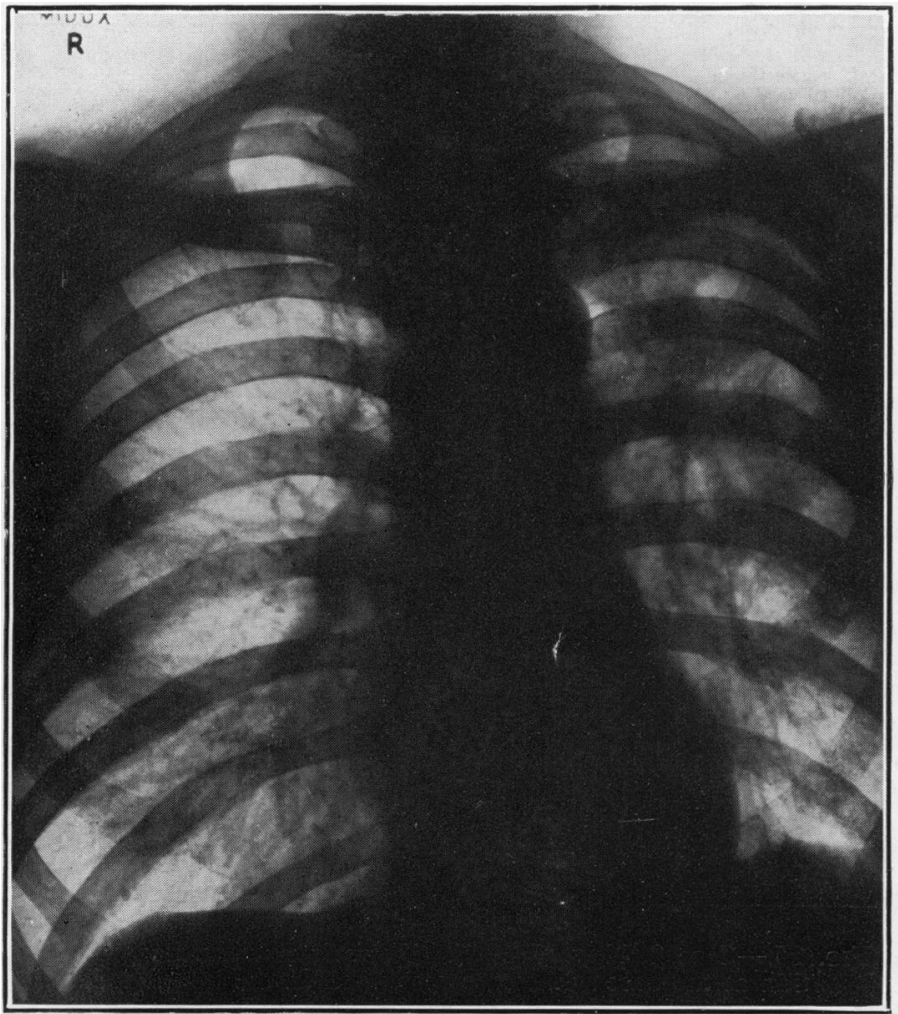

FIG. 20.-Case 1, Nov. 20, 1944. There has been considerable resolution, but there are still cavities.

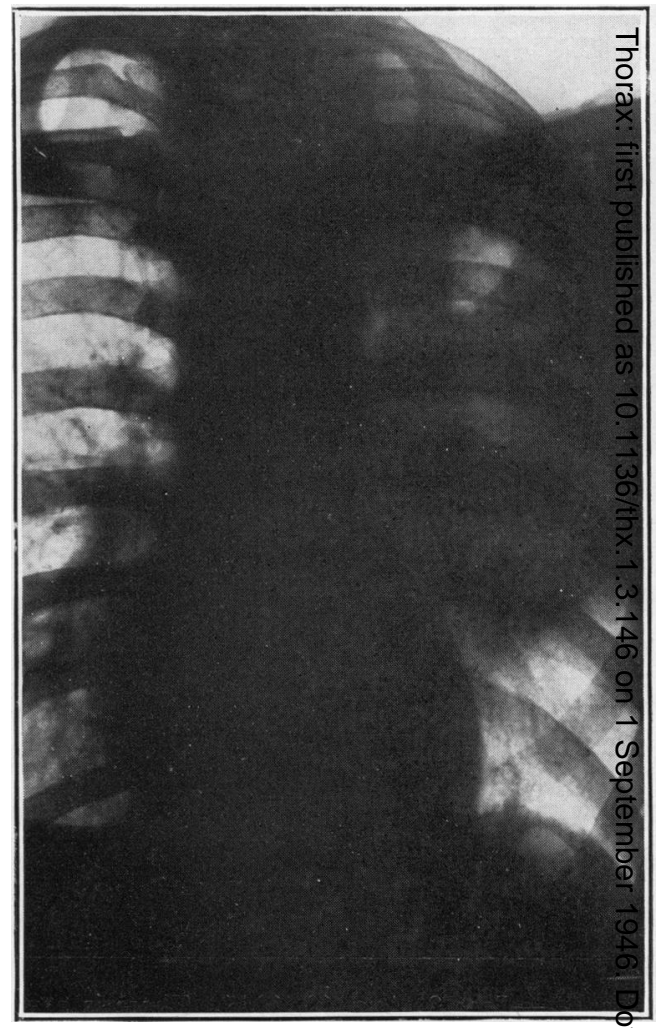

FIG. 19.-Case 1, May 19, 1944. The origina cavity persists. A fresh cavity has forma just below, and there is extension of the lesion downwards into the dorsal lobe. $\stackrel{\mathbb{Q}}{2}$

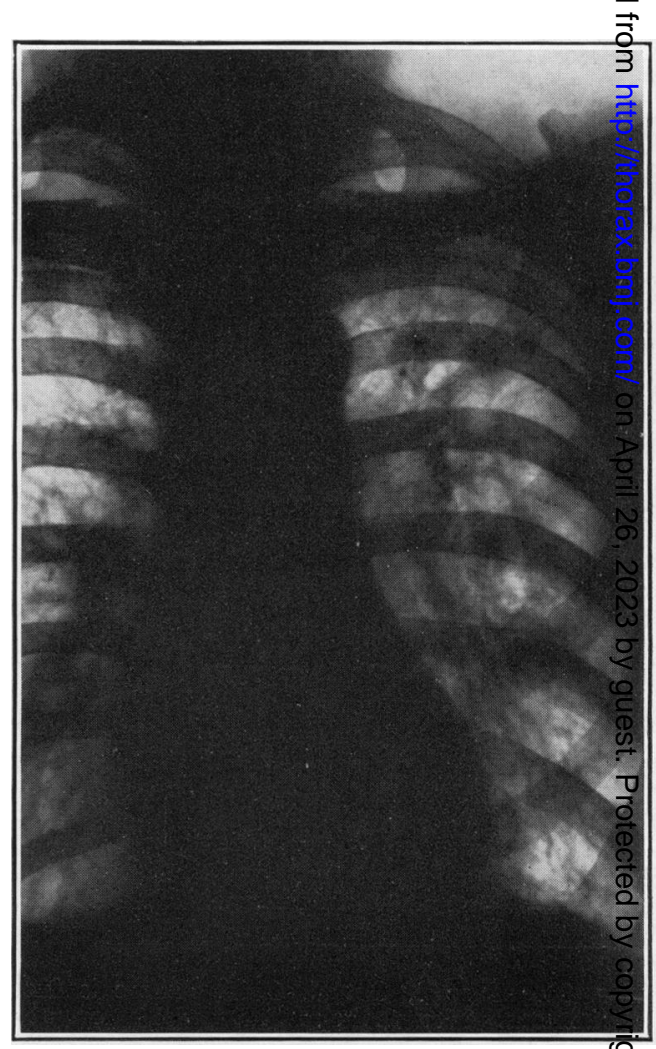

FIG. 21.-Case 1, April 29, 1946. There is con siderable resolution of the lesion but some residual bronchiectasis and probably persistent cavities. 


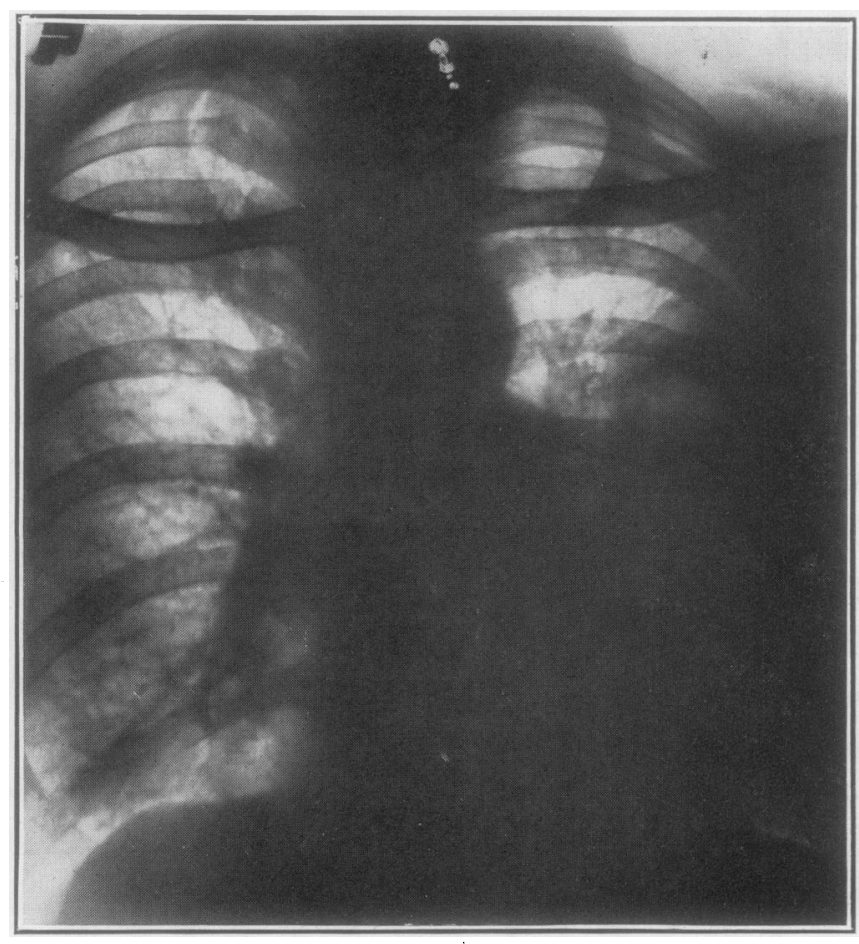

FIG. 22.-Case 2, Aug. 13, 1945. There is consolidation in the mid and lower zones with a cavity in the mid zone.

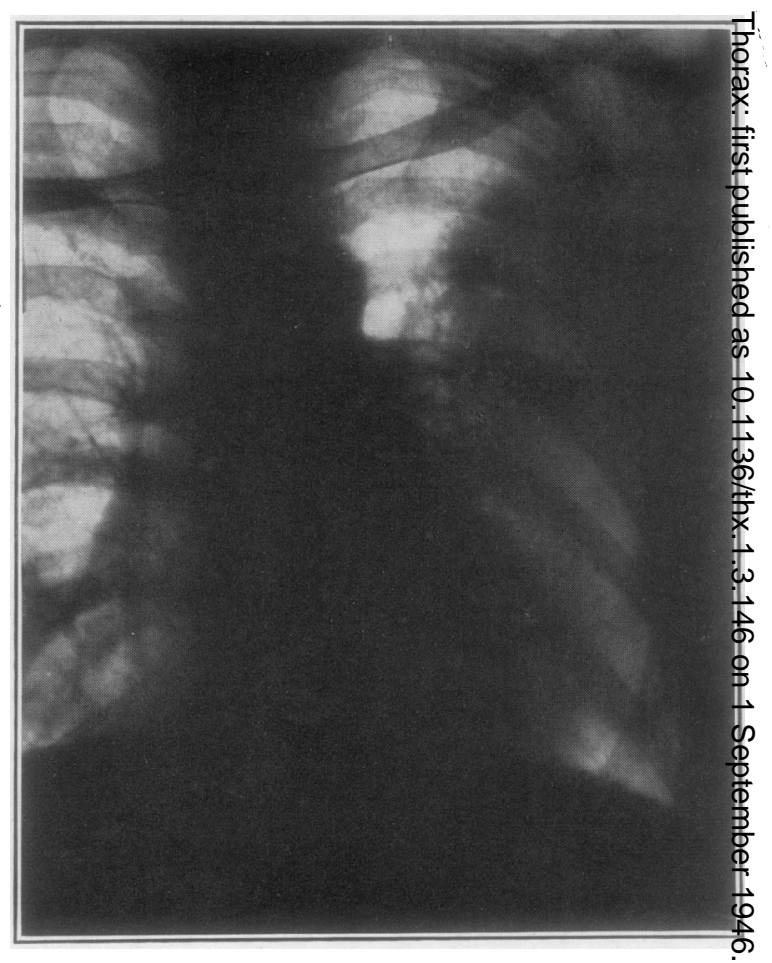

Fig. 23.-Case 2, Aug. 25, 1945. There is further? consolidation in the upper zone with a fresh cavity; the original cavity is no longer visible. There has been resolution at the base.

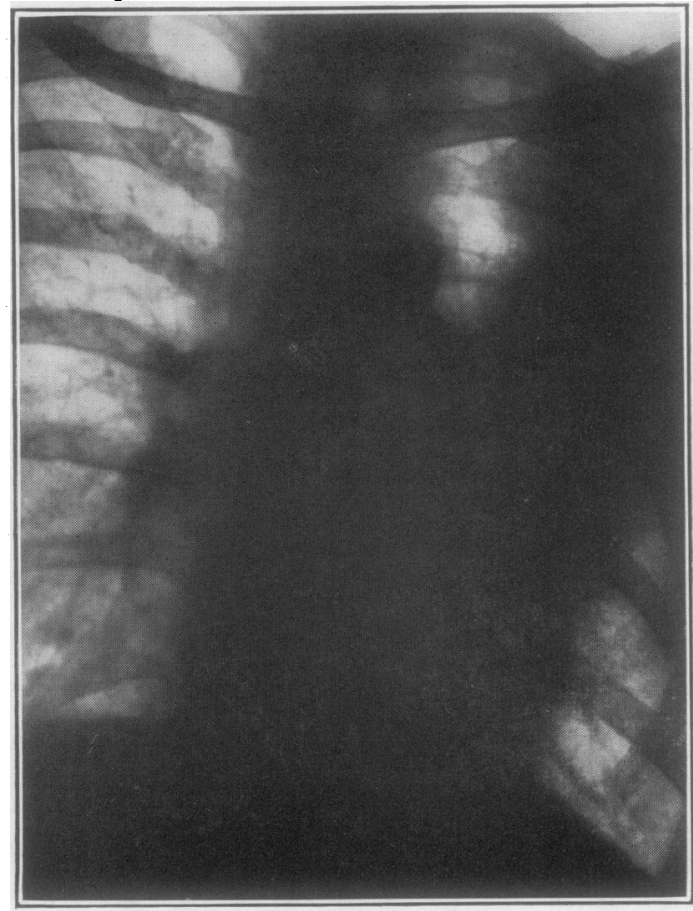

Fig. 24.-Case 2, Oct. 4, 1945. There is further extension to the apex and resolution at the base. Dense shadows in the left mid zone are artefact.

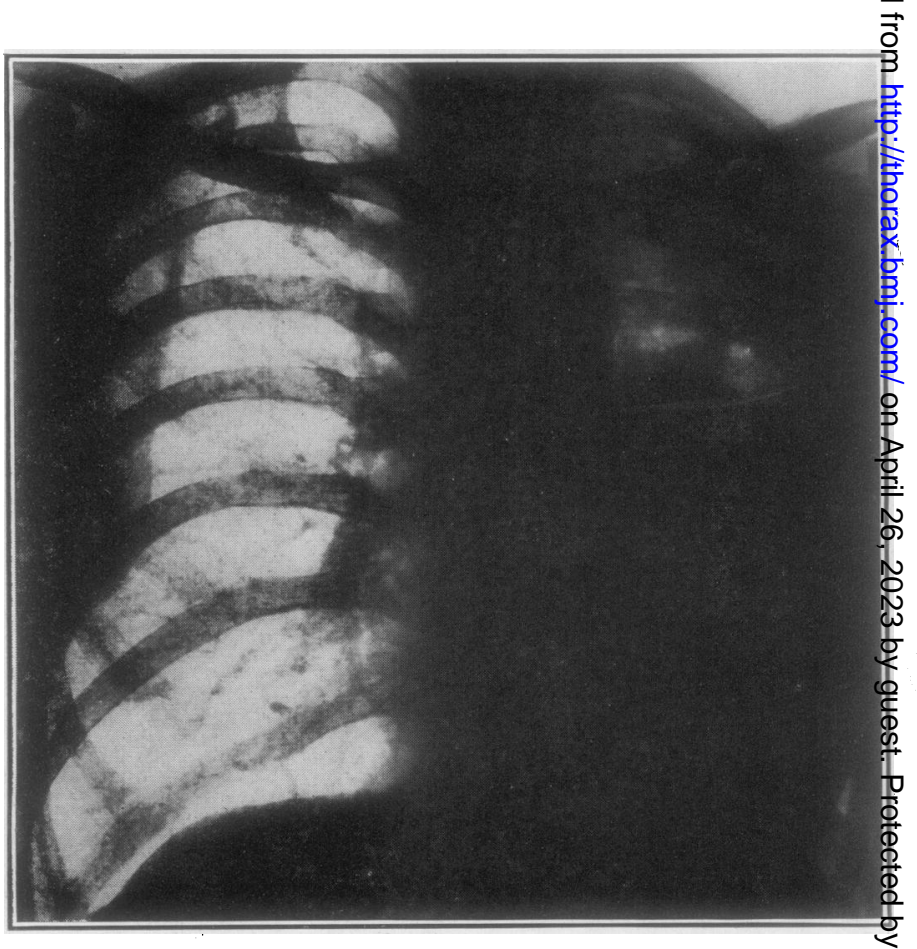

FIG. 25.-Case 2, Nov. 6, 1945. There is now further consolida@ tion at the base with some resolution in the upper zone. The cavity persists. I.ateral view at this date showed a cavity con taining a fluid level in the lower lobe, and some suggestio of a thin-walled cavity in the upper lobe. 
resonant to percussion, with normal air entry and breath sounds, and rhonchi scattered over the whole of the right lung; the left chest was dull to percussion, breath sounds being absent at the base, bronchial at the apex, and coarse crepitations were heard throughout the lung.

On Nov. 6, 1945, radiograph showed the heart displaced to the left, the left diaphragm being high and the right lung appearing clear. In the left lung there was patchy consolidation, associated with some collapse in all zones. There was evidence of a thin-walled cavity in the upper lobe and a small cavity containing a fluid level in the lower lobe (Fig. 25).

Bronchoscopy.-The left bronchial tree was inflamed and pouring pus from all branches. No obstruction or other abnormality was seen. It was thought that the patient was likely to die unless the lung was removed. He was, therefore, treated by systemic penicillin and blood transfusion. Haemoglobin rose to $90 \%$, the temperature, pulse rate, and respirations fell, and sputum was reduced to $12 \mathrm{oz}$. a day.

On Nov. 20, 1945, left pneumonectomy was performed. Before the anaesthetic the left main bronchus was occluded with a rubber balloon to prevent spill-over. The lung was adherent to the chest wall, but the adhesions were fairly easily separated with the finger. The hilar structures were dissected, the vessels ligated separately. The bronchus was closed with one layer of over-end linen thread sutures and covered with a pedicled intercostal muscle graft. The chest was closed without drainage. There were no unusual technical or anaesthetic difficulties.

Pathological Specimen.-The left lung was shrunken, with ragged adhesions and thickened inter-lobar septum (Fig. 9). A large ramifying abscess in the central part of the upper lobe was filled with a greyish, purulent slough containing collagen but no elastic fibres. It had a chronic inflammatory wall, with a surface pyogenic in most parts but in places covered by spreading epithelium (Figs. 10 and 11). There was surrcunding fibrosis, and, iurther out, accumulations of foam cells in alveoli-i.e., chronic pneumonia ; also foci of necrosis infiltrated with histiocytes. In places there was emphysema. One of several s.nall abscess cavities in the upper lobe contained a whitish slough in which collagen, but not elastic, fibres were demonstrable. One side of this had a squamous epithelial lining. In the lower lobe there was extensive carnification, discrete and lobular anteriorly but confluent in the hypostatic parts. Several small abscess cavities were situated between the normal and fibrosed parts in the lower lobe. In the lingula and the sector above, there was bronch:ectasis. The lymph glands showed hyperplasia.

Result.-The patient recovered satisfactorily from the operation, the only complication being some bronchitis in the right lung which had existed before the operation. He is now, six months later, quite well and free of all symptoms.

Comment.-This case illustrates the treatment of fulminating suppurative pneumonitis by pneumonectomy. It shows that good results can be obtained if the patient's condition can be improved sufficiently by penicillin and blood transfusion. It also illustrates that the operation in such a case is technically easier and accompanied by less shock than in patients with very chronic disease in whom the pleural adhesions have had time to become organized and fibrotic.

Case 3. Chronic type with clinical recovery.-A chief stoker, R.N., aged 39, in 1933 had an attack of left pleurisy; but no ill effects remained. After 1939, when his ship was sunk and he was in the sea for a long time, he suffered from recurrent colds and pain in the shoulder. In April, 1943, while doing full duty in difficult climatic circumstances, he developed cough with sputum and lassitude. A diagnosis of tuberculosis or abscess was tentatively made. 


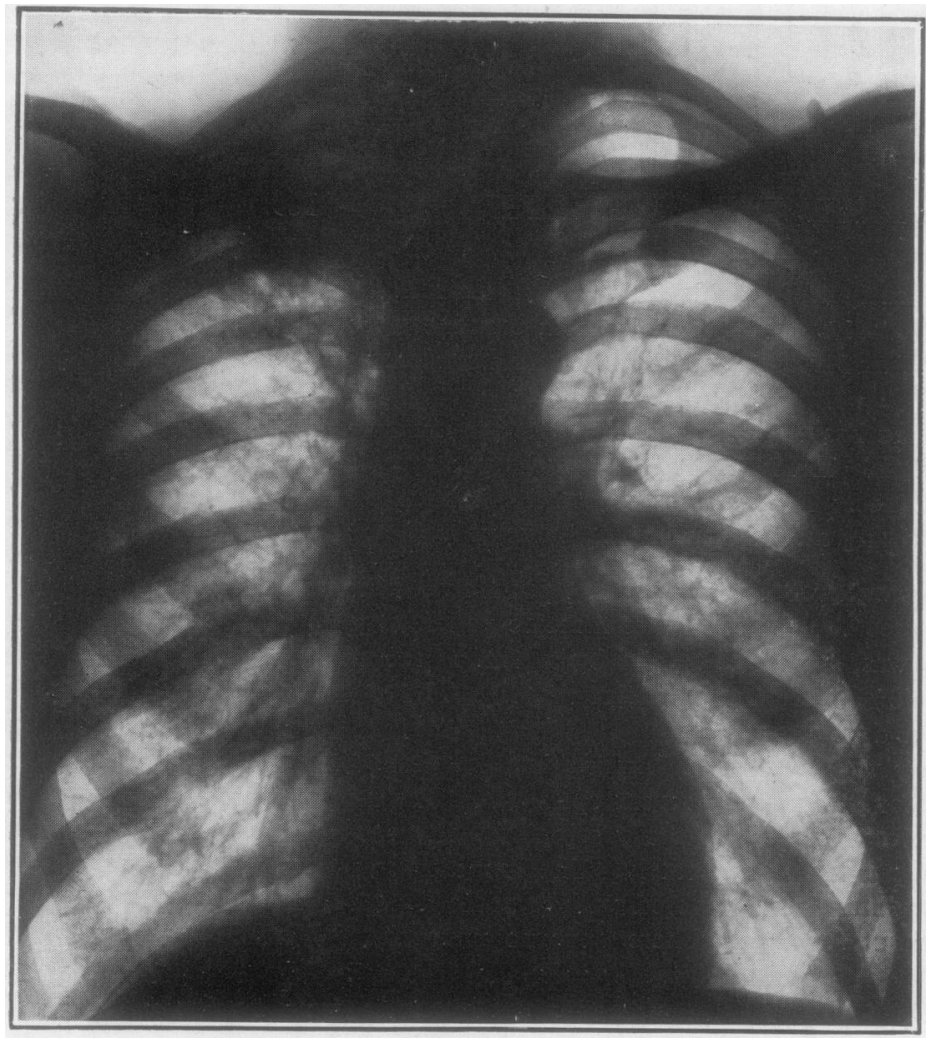

Fig. 26.

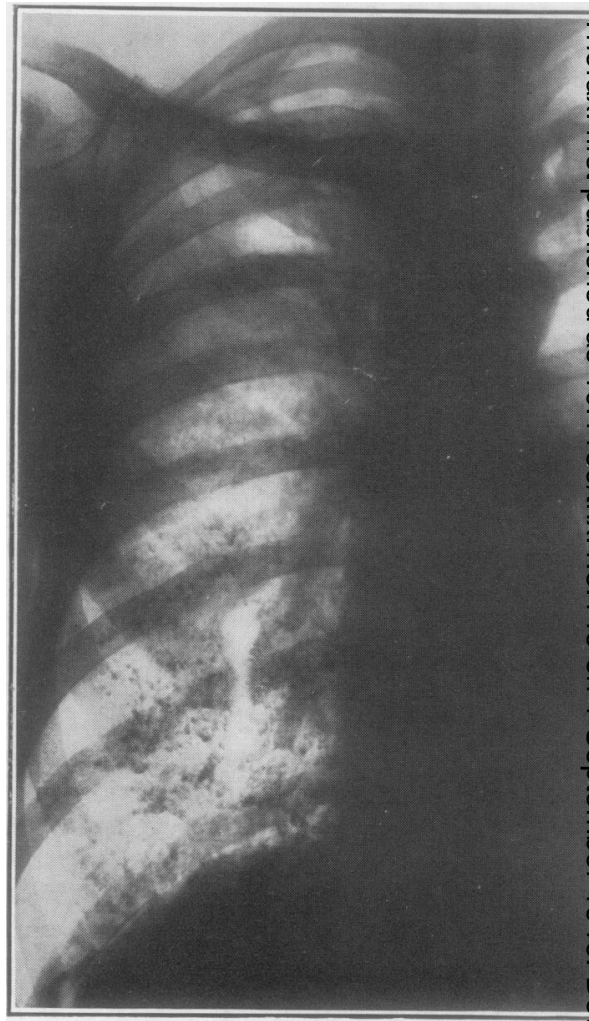

FIG. 27.

FIG. 26.-Case 3, Sept. 22, 1943. There is partial consolidation in the right upper zone with a cavity above the clavicle.

FIG. 27.-Case 3, Dec. 14, 1943. There has been extension of the lesion into the mid zone, and a fresh cavity has formed below the clavicle.

Fig. 28.-Case 3, Jan. 6, 1944 . Three weeks later: considerable resolution of the lesions in both the upper and mid zones. 


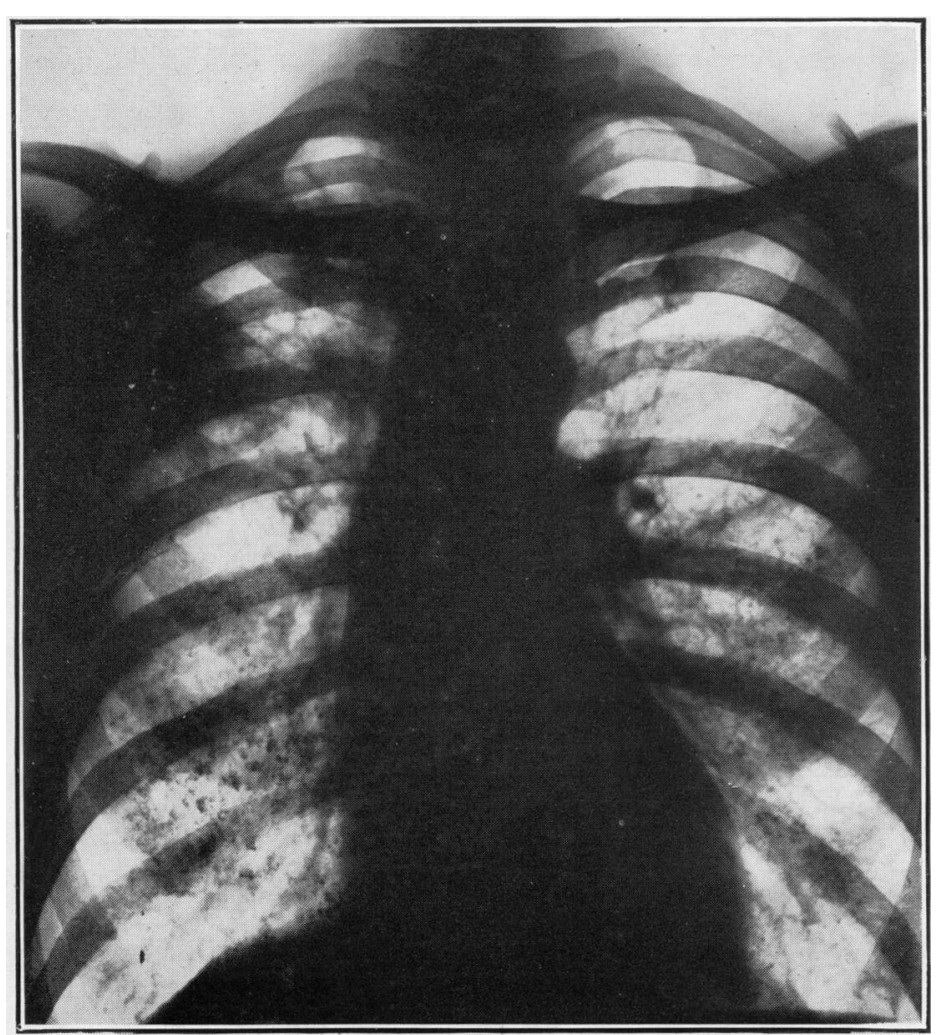

Fig. 29.

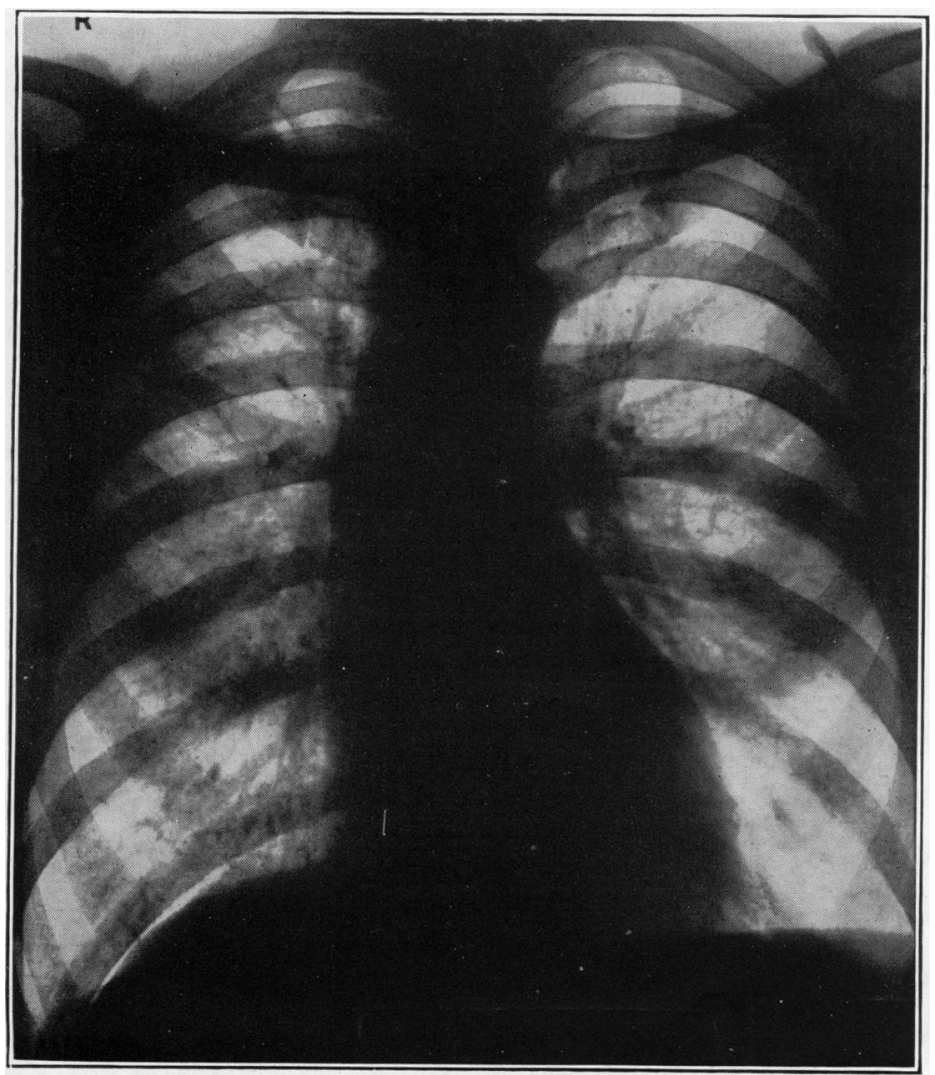

FIG. 31 .

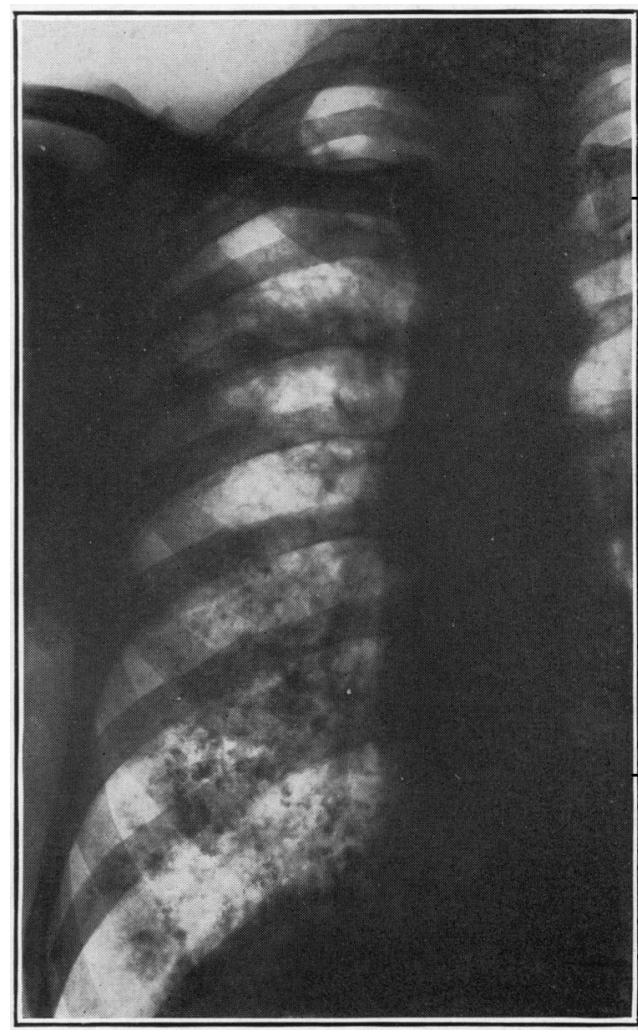

FIG. 30

FIG. 29.-Case 3, Feb. 14, 1944. Some further consolidation is present at the junction of the upper and mid zone.

FIG. 30.-Case 3, April 11, 1944. There is a fresh cavity at the junction of the right upper and middle zones towards the axilla.

FIG. 31.-Case 3, March 27, 1945. This last radiograph shows still a small cavity peripherally at the junction of the upper and middle zones. 
In Sept., 1943, he was admitted to Harefield Sanatorium. There was some loss of weight, severe cough with sputum up to $15 \mathrm{oz}$. a day and occasional staining, pain in the chest, and some clubbing of the fingers. Vital capacity was $3,280 \mathrm{c.cm}$., haemoglobin $72 \%$, and white blood count 13,200 per c.mm.; sputum contained masses of grampositive cocci ; no fungi were found, and repeated examinations revealed no tubercle bacilli. A radiograph on Sept. 22, 1943, showed partial consolidation in the right upper zone with a cavity above the clavicle (Fig. 26). Bronchogram showed a normal bronchial tree, apart from lack of filling in the region of the lesion. Eight weeks later lesion had extended into the middle zone, and a month later still a fresh cavity had formed below the clavicle (Fig. 27).

A radiograph on Jan. 6, 1944, showed extensive consolidation at the junction of the upper and mid zones (Fig. 28). Another, on Feb. 14, showed further consolidation at the junction of the upper and mid zones (Fig. 29). On April 11 there was a fresh cavity at the junction of the right upper and middle zones towards the axilla (Fig. 30).

March 27, 1945.- There had been gradual resolution of the lesion during the year, but the last radiograph suggested that there was still a small cavity peripherally at the junction of the upper and middle zones (Fig. 31). The final bronchogram showed a normal bronchial tree on the right side, with the exception of lack of filling of the area of the suspected cavity.

The clinical course was remarkable for the good general condition, the only complaint, apart from the cough and sputum, being some reduced exercise tolerance. There was slight fever with exacerbations. The patient returned to light work in July, 1944-15 months after the onset-had one relapse in Dec., 1944, and since then has been in good health and at work of moderate physical requirements. There was no response to repeated courses of sulphonamide drugs or to penicillin.

Comment.-After a mild acute phase, the chronic stages were characterized by profuse sputum and three or four "flare-ups" over a year and a half. The man has been able to return to work. Radiographs showed considerable resolution of the lesion.

Case 4. Progressive type with relapses.-A painter, aged 53, had always been healthy and had been able to do 6 rounds of boxing until shortly before his illness. In May, 1943, there was pain in the right chest suggestive of pleurisy, with cough and thick, offensive sputum. The condition was diagnosed as influenza, and he returned to work in three weeks. One month later, pain, malaise, and cough recurred, with fever and slight haemoptysis. A diagnosis of right upper pneumonitis was made. Sputum contained pneumococci type 3.

In July, 1943, the patient was admitted to Harefield Sanatorium. He had fever up to $101^{\circ} \mathrm{F}$., and cough with $8 \mathrm{oz}$. of purulent and occasionally blood-stained sputum. There was a stabbing pain between the shoulder blades and in the right axilla. The loss of weight was over 1 stone. Radiograph on July 5, 1943, showed an area of collapse and consolidation in the right upper zone, the diagnosis lying between neoplasm and pneumonitis (Fig. 32).

Eleven days later there was slight extension of the lesion and cavity formation (Fig. 33). On Aug. 15 the lesion had spread into the right mid zone but was probably still in the right upper lobe. A Monaldi tube had been introduced a few days previously but was not in any definite cavity (Fig. 34). Bronchoscopy showed, in addition to much pus, a granulomatous polypus in the right upper orifice; biopsy showed inflammatory changes in the bronchial mucosa. Four bronchoscopies showed inflammatory changes and pus only.

On admission, haemoglobin was $60 \%$, and white blood count 9,700 per c.mm. There were Gram-positive cocci in the sputum, but no tubercle bacilli. Vital capacity was $1.900 \mathrm{c} . \mathrm{cm}$. Conservative treatment with courses of sulphathiazole had little beneficial effect. In Sept., 1943, an ineffectual attempt was made to drain the cavitated area with a fine tube. White blood count at this time was 15,400 per c.mm. ( $82 \%$ polymorphs). Sputum was occasionally blood-stained ( 7 to $10 \mathrm{oz}$. per day). On Sept. 9 a radiograph 


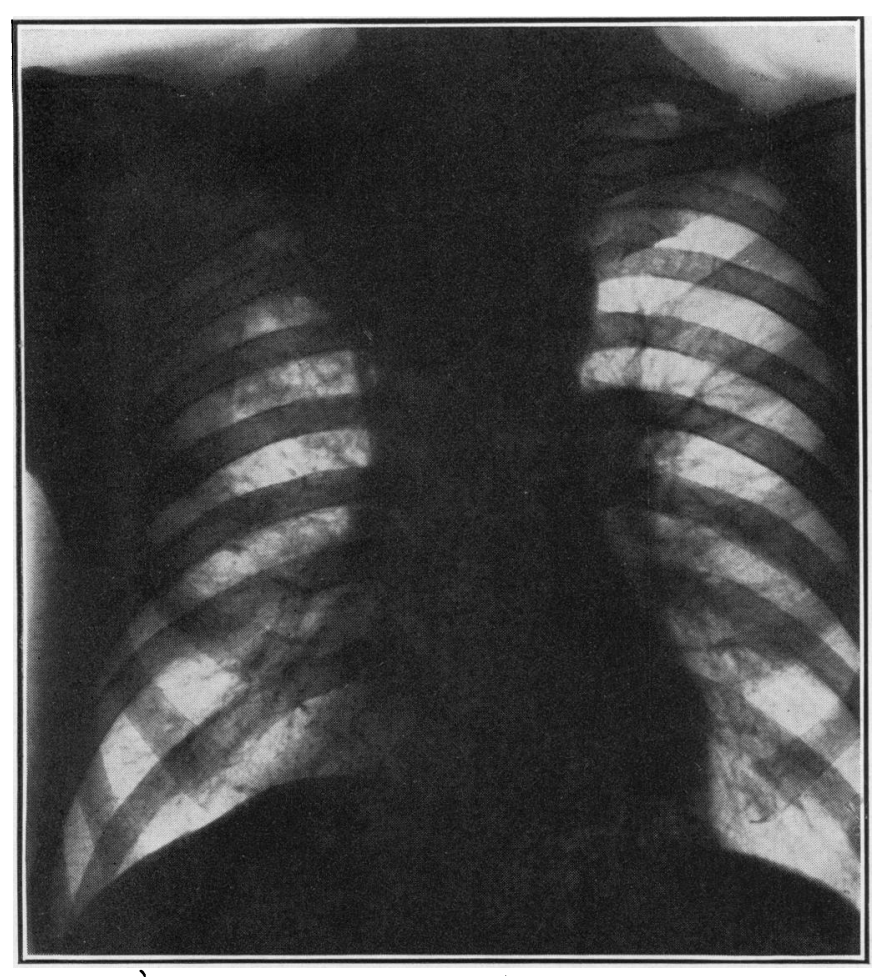

Fig. 32.

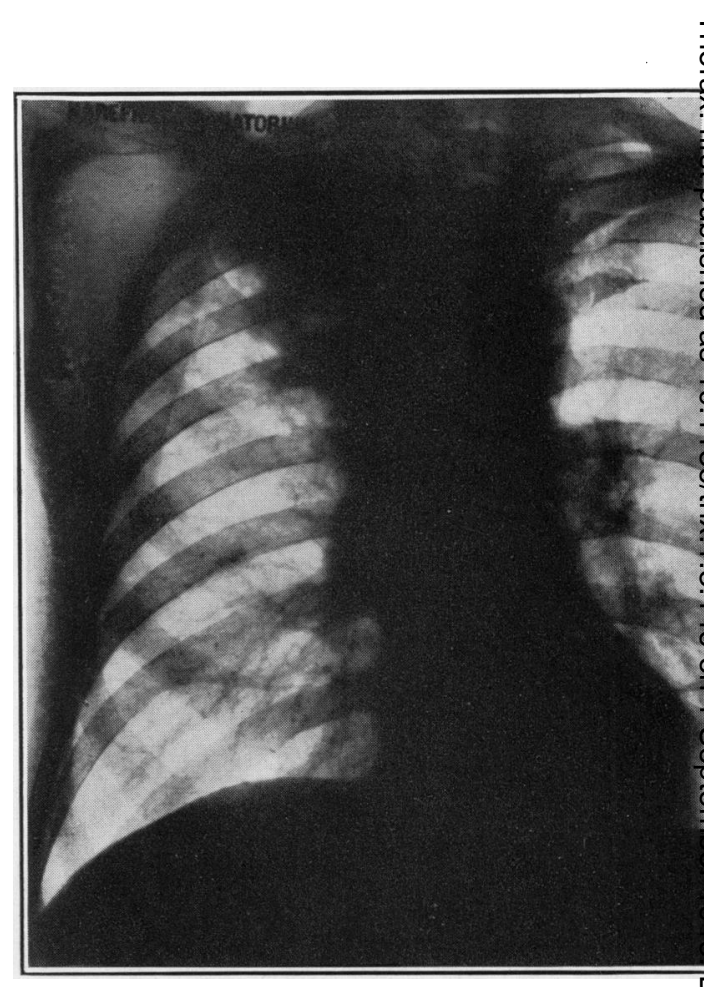

Fig. 33.

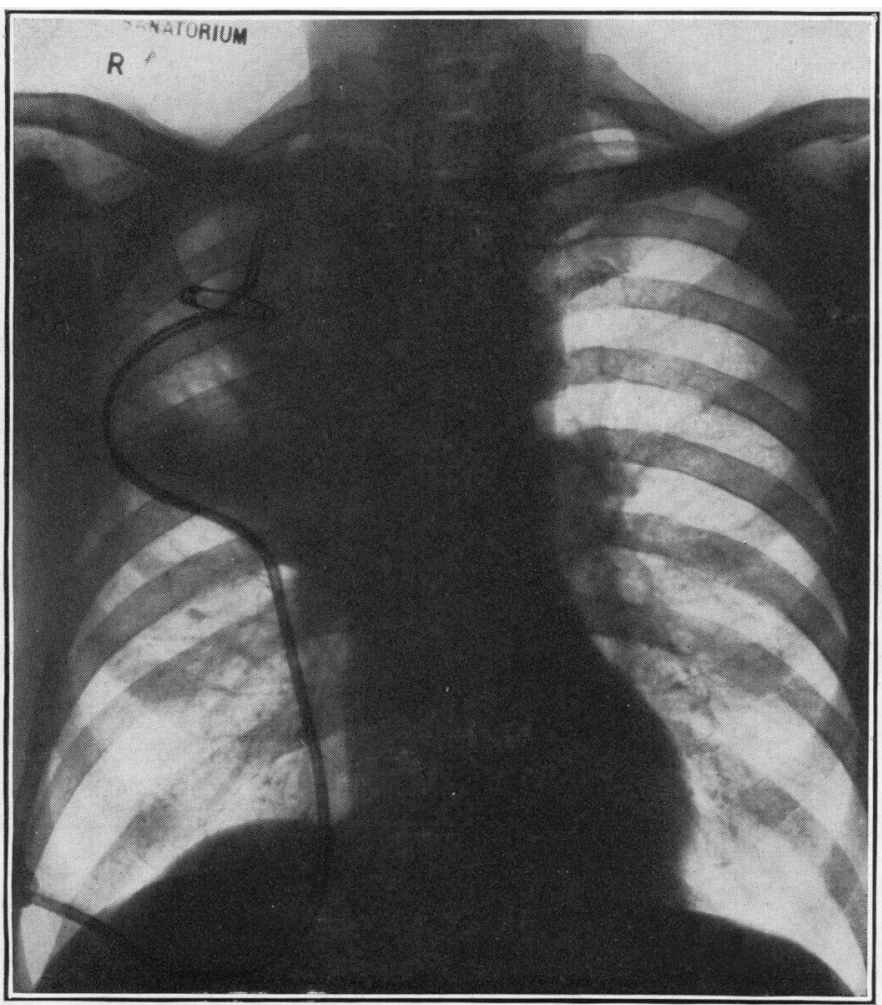

Fig. 32.-Case 4, July 5, $1943 . \quad$ There is an area of collapse and consolidation in the right upper zone, the radiological diagnosis lying between neoplasm and pneumonitis.

FIG. 33.-Case 4, July 16, 1943. There is now a cavity below the clavicle.

FIG. 34.-Case 4, Aug. 25, 1943. There is an extension of the lesion into the right mid zone, but probably still in the right upper lobe. A Monaldi tube has been introduced, but is not in any cavity. 


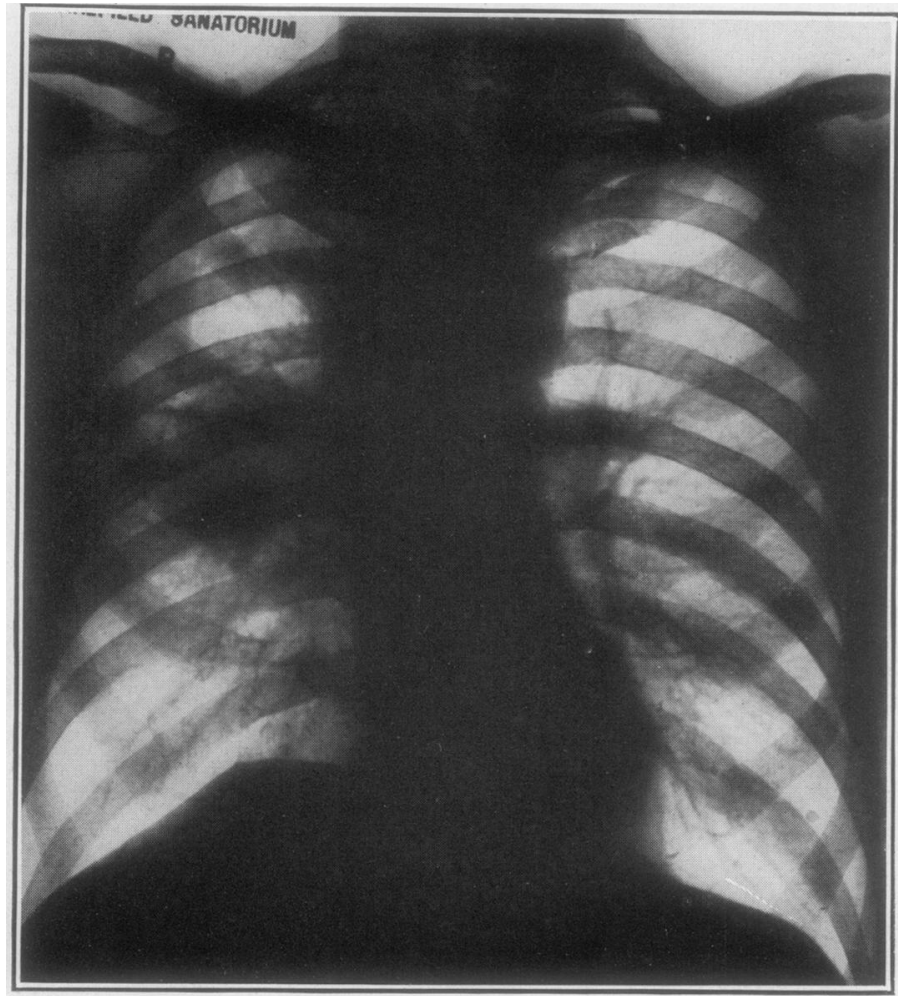

FIC. 35.-Case 4, Sept. 11, 1943. There is considerable resolution of the lesion in the upper lobe, but a fresh lesion in the mid zone, which is situated anteriorly and has crossed the fissure into the middle lobe.

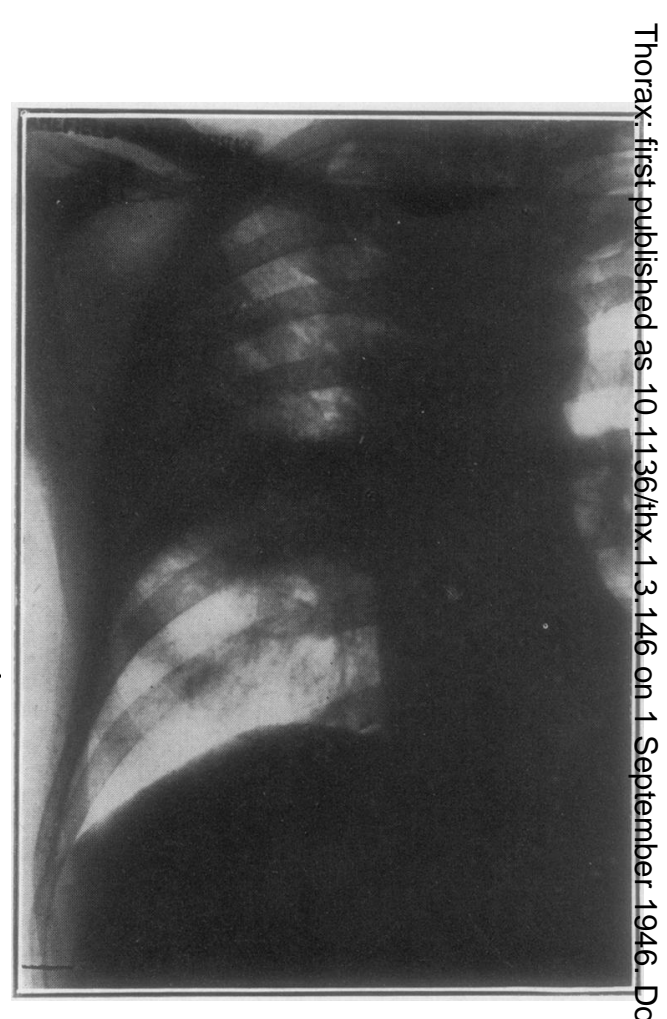

FIG. 36.-Case 4, Sept. 29. 1943. The lesion in the right middle zone has spread and now reaches the periphery.

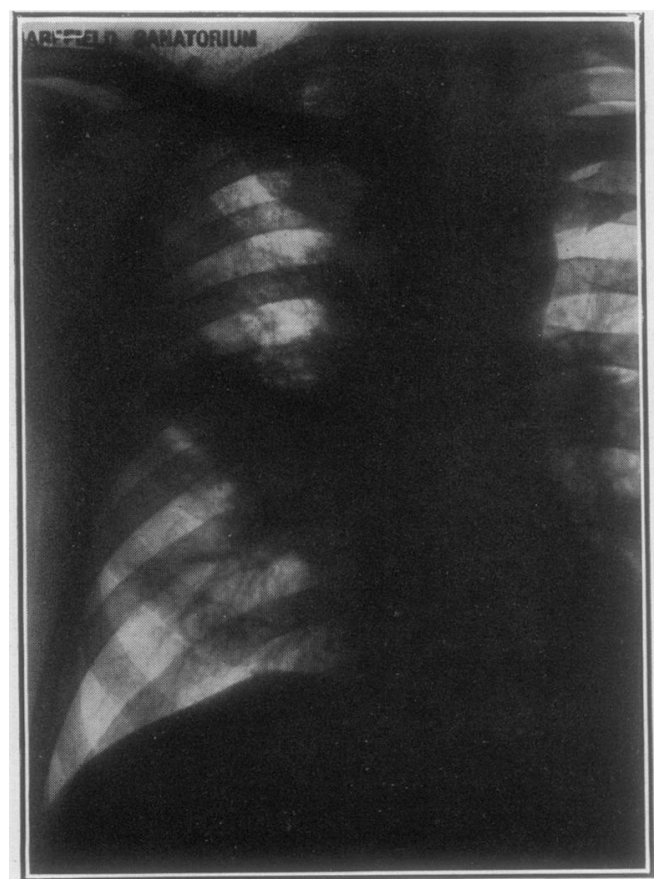

FIG. 37.-Case 4, Oct. 9, 1943. There is some resolution of the lesion in the right mid zone.

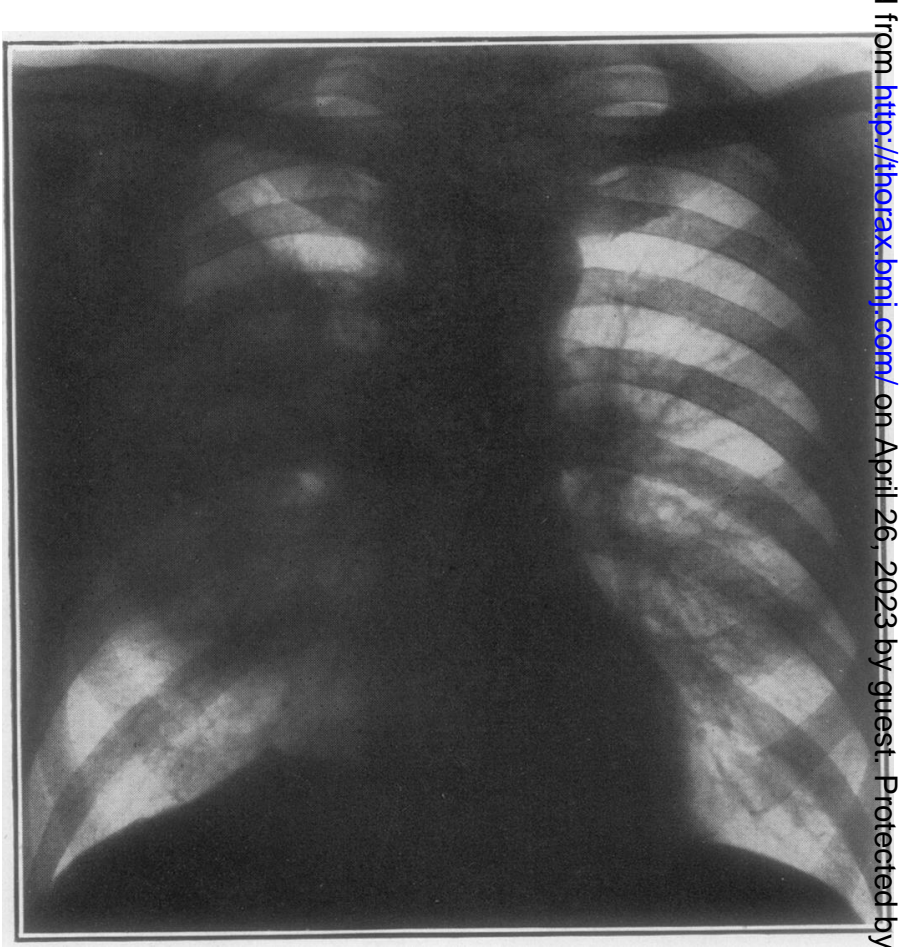

FIG. 38.-Case 4, April 21, 1944. There is again considerablê extension of the lesion, the appearances being due to collapse and consolidation in the middle lobe, and the anterior part of the base of the upper lobe, with evidence of softening in the upper lobe. 
showed considerable resolution of the lesion in the upper lobe, but a fresh lesion in the mid zone which was situated anteriorly and had crossed the fissure into the middle lobe (Fig. 35). After a fortnight the condition improved. Bronchoscopy showed inflamed mucosa with granulations round the upper lobe orifice. There was less fever, and sputum was reduced to 4 to $5 \mathrm{oz}$. Vital capacity was $2,550 \mathrm{c.cm}$. The cavitation persisted. On Sept. 29 the lesion in the right middle zone had spread and now reached the periphery (Fig. 36). By Oct. 9 there was some resolution of the lesion in the right mid zone (Fig. 37).

In Nov., 1943, the patient left the hospital, still with cavitation, cough, and 3 to $4 \mathrm{oz}$. of sputum. When seen 5 months later he had an extensive flare in the lung and was incapacitated for some weeks.

In April, 1944, there were further exacerbations with some subsequent clearing; the man continued to work when afebrile. A radiograph on April 21 showed extension of the lesion, collapse and consolidation in the middle lobe and the anterior part of the base of the upper lobe, and evidence of softening in the upper lobe (Fig. 38). Operation was suggested but was refused, and the patient died some months later.

Comment.-This patient showed exacerbations at fairly regular intervals. Surgical treatment would have been attempted if he had been temperamentally suitable.

Case 5. Chronic type treated by pneumonectomy.-A bus driver, aged 37, in March, 1938, complained of pain in the right chest and malaise for a few days, followed by persistent cough and sputum. In Sept. pneumonia was diagnosed.

In Oct., 1938, he was admitted to the London Chest Hospital with a diagnosis of chronic lung abscess, right upper lobe. Bronchograms showed a normal bronchial tree except for non-filling in the region of the lesion. Radiograph on Oct. 12 showed partial consolidation in the right mid and lower zones, and a high diaphragm (Fig. 1). By Oct. 20 there was some clearing of the lesion at the base (Fig. 2). A bronchogram, on Oct. 26, showed a normal right bronchial tree, with the exception of lack of filling in the region of the lesion in the mid zone (Fig. 3). Another radiograph on Feb. 1, 1939, showed the base again clearer but an extension of the lesion in the base of the upper lobe (Fig. 4). In March, 1939, he returned to work. On Aug. 10, 1939, there was further consolidation and collapse at the base (Fig. 5).

In Sept., 1939, he was called up as a reservist in the Army and three months later developed cough, dyspnoea, malaise, and haemoptysis. In Feb., 1940, he was discharged from the Army owing to persistence of symptoms, but in March he returned to work as a bus driver. Except for short periods, when there were exacerbations of symptoms, he worked till 1942. A radiograph on May 6, 1942, showed an extension of the lesion into the upper zone with evidence of excavation in the upper and middle zones and considerable fibrotic change, particularly at the base. In Nov., 1942, he could no longer work owing to lassitude, dyspnoea, anorexia, cough with copious sputum, and occasional haemoptysis. On June 21,1943 , a radiograph showed a thin-walled cavity at the apex, and further consolidation at the base, with a cavity (Fig. 6).

In Sept., 1943, he was admitted to Harefield Sanatorium. He weighed $11 \mathrm{st} .10 \mathrm{lb}$., and his vital capacity was $2,000 \mathrm{c.cm}$. He was dyspnoeic on exertion and had clubbing of the fingers. Haemoglobin was $80 \%$; white blood count 8,000 per c.mm. Sputum was purulent-6 oz. per day-and sometimes blood-stained; pneumococci, streptococci, and staphylococci were present, but no tubercle bacilli. The chest showed signs of emphysema, with consolidation throughout the right lung and cavitation at the apex. A radiograph on admission showed extensive fibrotic lesions in all zones of the right lung, with thin-walled cystic appearances in the upper and mid zones, and some consolidation towards the base (Fig. 7). A bronchogram on Oct. 14 showed extensive cystic bronchiectasis in the right upper and middle zones, and also cystic areas situated in the upper lobe 
anteriorly (Fig. 8). Another on Nov. 6 showed cavities in the right lower lobe also. Bronchoscopy showed general inflammation and much pus in the right bronchial tree. The left lung was normal.

In view of the long history with gradual progress of the disease, right pneumonectomy seemed the best method of treatment and was performed on Nov. 16, 1943. The operation was made difficult by dense pleural adhesions over the whole lung. Two hours elapsed before the lung was completely freed. Individual dissection of the hilar structures was fairly simple. As the lung was torn, with gross soiling of the pleura, a drainage tube was inserted. The separation of the lung had resulted in severe shock, and 4 pints of blood in all were given during and after the operation.

Description of Pathological Specimen.-The right lung was shrunken and indurated, ragged from generalized adhesions. Section revealed gross changes (see Fig. 12). In the apical sector of the upper lobe there was a large bulla with fibrous wall and smooth, unlined surface, having a slit-like bronchial opening. The greater part of the antero-lateral sector consisted of a large cavity into which ran the first four branches of the sector bronchus, and which extended downwards and joined with smaller cavities in the proximal part of the middle lobe. Behind and above it were other cavities which did not intercommunicate, though one had a trabeculum running across it. All these spaces were healed abscess cavities, the epithelium lining them being of the respiratory type. In most places this was superimposed on scar tissue containing no muscle, cartilages, or glands. In places where the original wall of the ulcerated bronchus had survived, these structures persisted. There was very little active inflammation, but the dark spot in the large cavity in Fig. 12 was an area of ulceration surrounded by a ring of squamous metaplasia, as shown in Fig. 13. Two of the smaller cavities contained partly calcified pneumoliths (probably derived from sloughs). In the central part of the lower lobe there was a large irregular chronic abscess surrounded by a wide zone of dense fibrosis in which there was lymphoid hyperplasia round the bronchioles. The wall of this abscess was composed of chronic inflammatory granulation tissue, in places lined by well-differentiated squamous epithelium with prickle cells and rete pegs (Figs. 14 and 15). The lymph glands were greatly enlarged by chronic inflammatory hyperplasia.

Result.-The patient recovered satisfactorily from the operation, and the empyema healed without thoracoplasty. He was free from cough and sputum, and his weight increased by $1 \frac{1}{2}$ stone. He has been able to do light work, but he is still dyspnoeic on exertion owing to emphysema and attacks of bronchitis in the left lung.

Comment.-This case illustrates the chronicity of the condition. When the patient was admitted to hospital five years after onset, the appearances suggested "congenital cystic disease" of the lung, and, even after histological examination of the specimen which had been removed, this diagnosis might have been maintained had it not been for the bronchograms carried out five years previously which had shown a normal bronchial tree. It also illustrates the technical difficulties and the shock involved in performing pneumonectomy on a patient with so long a history.

Case 6. Chronic type treated by pneumonectomy.-A dock labourer, aged 36, in Feb., 1943, had cough with slightly offensive sputum and noticeable halitosis. In March, 1943, he was admitted to hospital with a diagnosis of lung abscess at the right base. No improvement occurred with postural drainage. A two-stage drainage operation was attempted, but no abscess cavity was found. A further operation for drainage also failed. The sputum decreased somewhat but there was occasional staining. On April 22 a radiograph showed an area of consolidation and collapse situated in the right lung (Fig. 39). On June 16 a bronchogram showed a normal bronchial tree with the exception of non-filling of the area involved in the right lower lobe (Fig. 40). 


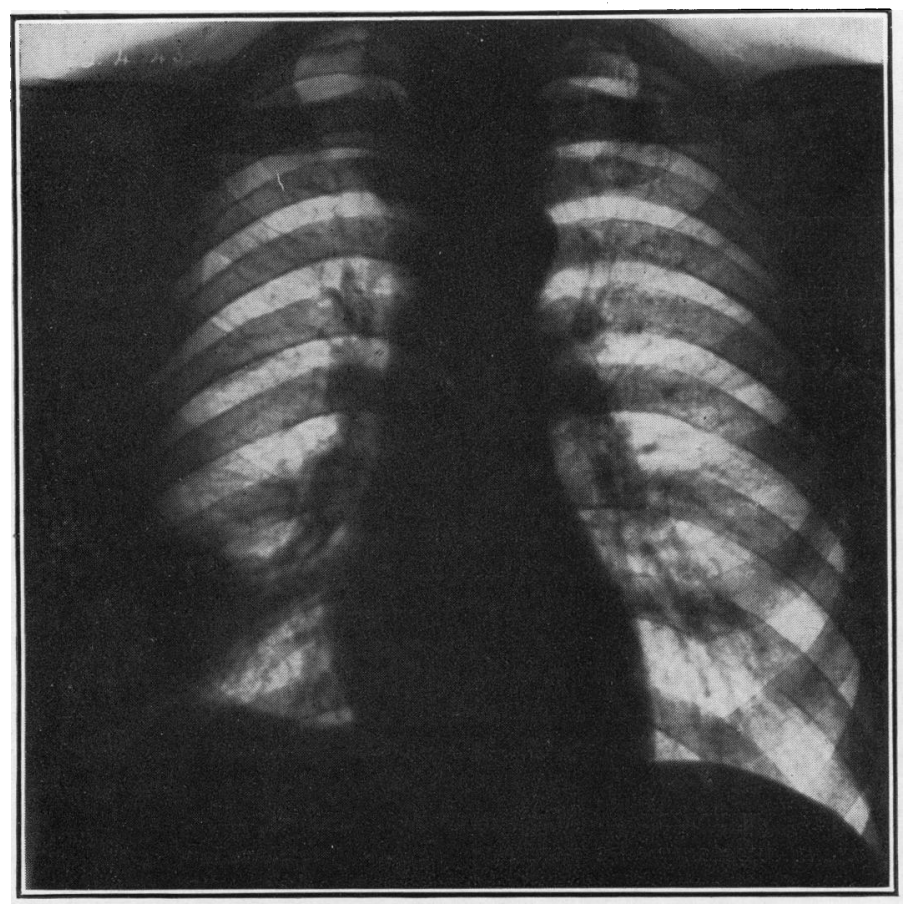

Fig. 39.-Case 6, April 22, 1943. There is an area of consolidation and collapse situated in the right lower lobe.

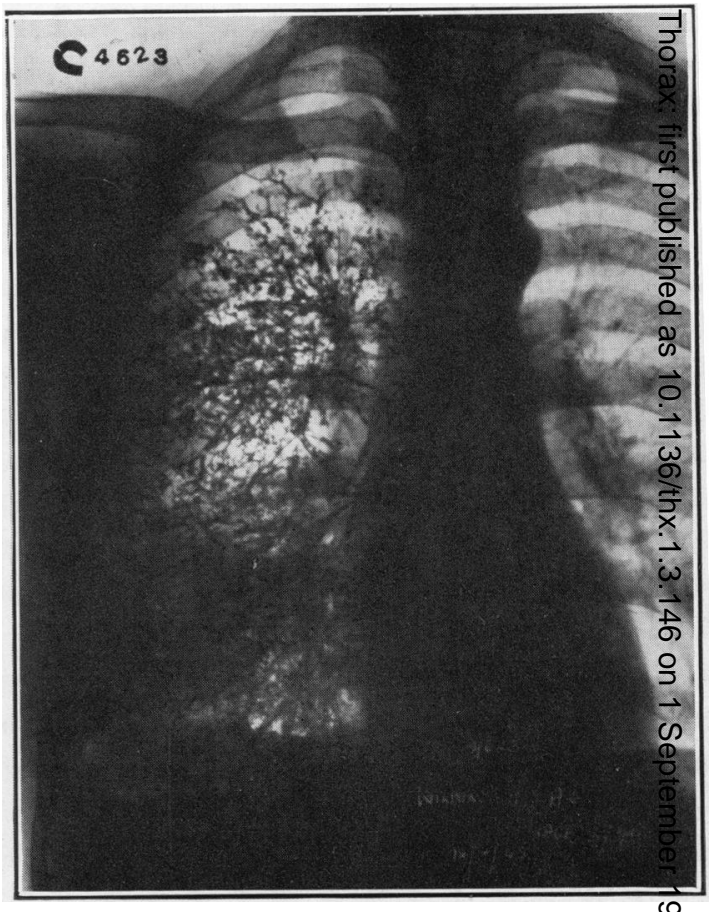

$\stackrel{0}{\stackrel{0}{*}}$

FIG. 40.-Case 6, June 16, 1943. Bronchogram shortly after onset shows normal bronchieal tree, with the exception of lack of filling \&f the area involved in the right lower lobe.

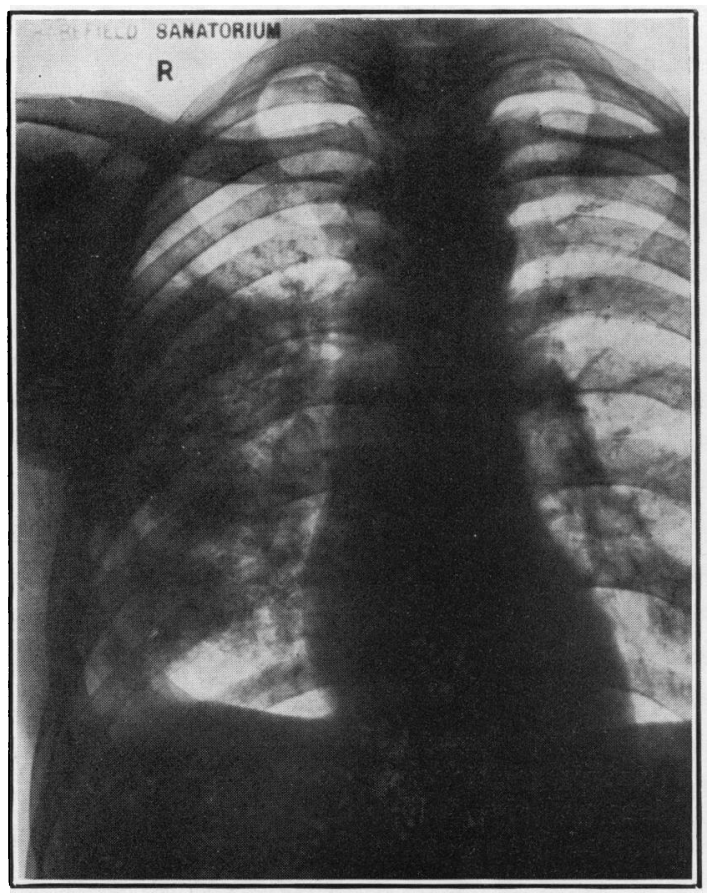

Fig. 41.-Case 6, Oct. 25, 1943. The consolidation has now spread to the middle zone, and there is some suggestion of softening in the lesion in the lower zone.

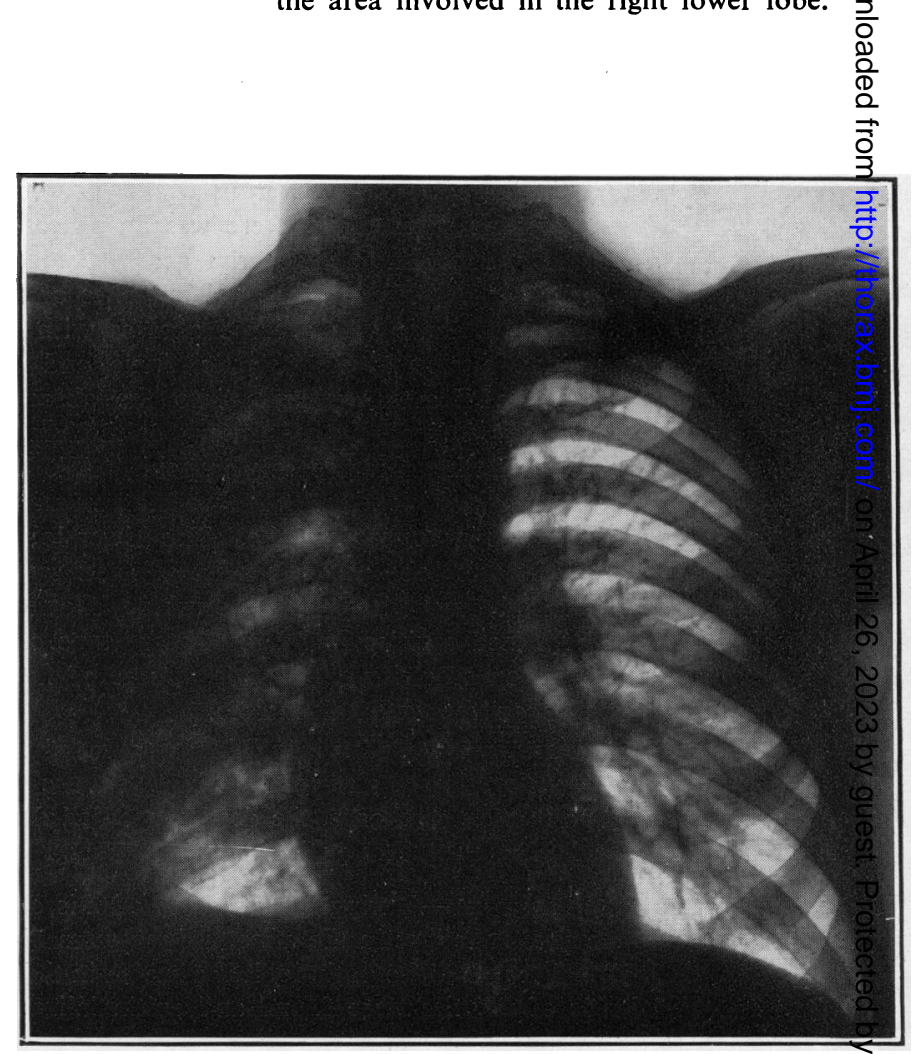

FIG. 42.-Case 6, Dec. 14, 1943. The lesion has now spreadg్ğ the apex, and there has been some resolution at the base. 
In Oct., 1943, he was admitted to Harefield Sanatorium. He had fever and cough with sputum up to $12 \mathrm{oz}$., and had lost about 1 stone in weight. The fingers were clubbed. Vital capacity was $2,450 \mathrm{c.cm}$. Examination of sputum showed normal bacterial flora and no tubercle bacilli. Haemoglob.n was $80 \%$; plasma protein 9.6 g. per $100 \mathrm{c.cm}$. Bronchoscopy showed little abnormality. During the next three months there were irregular bouts of fever, with slight response to sulphamezathine. Sputum varied between 8 and $14 \mathrm{oz}$. On Oct. 25 the consolidation had spread to the middle zone and there was some suggestion of softening in the lesion in the lower zone (Fig. 41). By Dec. 14 the lesion had spread to the apex, and there had been some resolution at the base (Fig. 42). A radiograph on Jan. 13, 1944, showed resolution of the lesion in the upper part of the upper zone, but a cavity overlying the second interspace (Fig. 43). By Feb. 18 there was further consolidation in the right upper zone, with excavation and narrowing of the right main bronchus (Fig. 44). A bronchogram on March 14 showed considerable bronchial dilatation and some cavity formation in the right upper lobe, a cavity in the right mid lobe, and another in the right lower lobe (Fig. 45).

In view of these progressive radiological changes the chances of resolution were regarded as small, and on April 20, 1944, right pneumonectomy was performed in the prone-headdown position. There were very dense adhesions over all pleural surfaces. The lung was dissected free except for a small area over the anterior mediastinum which had to be cut clear. The hilum was concealed by a large mass of glands and secured by combination of individual and mass ligature. The chest was closed without drainage. Two pints of blood were given during and after operation.

Description of Pathological Specimen.-The right lung was shrunken, with adhesions and thickening of the interlobar septa (Fig. 16). There was induration due to chronic inflammation. In the upper lobe there were 7 small cavities, lined with respiratory epithelium, by which the bronchi of the three sectors irregularly intercommunicated. The apex contained a large bulla with fibrous wall which communicated with several bronchi, and in the anterior part of the lobe there was an abscess extending across the interlobar septum. A slit-like epithelialized cavity ran across the centre of the middle lobe and communicated with both the medial and lateral branches of the middle lobe bronchus. In the distal part of this lobe there was a large abscess with a pyogenic surface and fibrous wall. This contained a slough with elastic tissue and collagen. Microscopic section revealed an "obliterated" artery running into the abscess. In the centre of the lower lobe there was a cavity, lined by respiratory epithelium, which communicated with branches of the dorsal and the three basal bronchi. All bronchi contained pus and showed chronic inflammatory thickening. The lumina were narrowed in many places. Slight bronchiectasis was present in the upper lobe. The lower lobe showed some disseminated foci of fibrosed lung, but this lobe was the least affected by chronic inflammatory changes. The glands which had escaped operative crushing showed little inflammatory enlargement. All the epithelialized cavities had a respiratory type of epithelialized lining which was often superimposed on scar tissue (Fig. 17). Some of these epithelialized abscess cavities lay deep to grooves on the external surface.

The post-operative condition was satisfactory, with reduction of sputum to a trace. A broncho-pleural fistula developed on the 10th day, and the chest was drained. By July, 1944, on discharge, the dead space had diminished considerably in size. Vital capacity was $1,400 \mathrm{c} . \mathrm{cm}$. The patient gained almost 1 stone in weight and had no cough or sputum.

Comment.-During the progress of this case the actual development of secondary and permanent changes in the affected lung were observed. Pneumonectomy gave a satisfactory clinical result. The pathological changes in the excised lung were significant in that different forms of cavities were found and epithelialization of some of these spaces was recognized. 


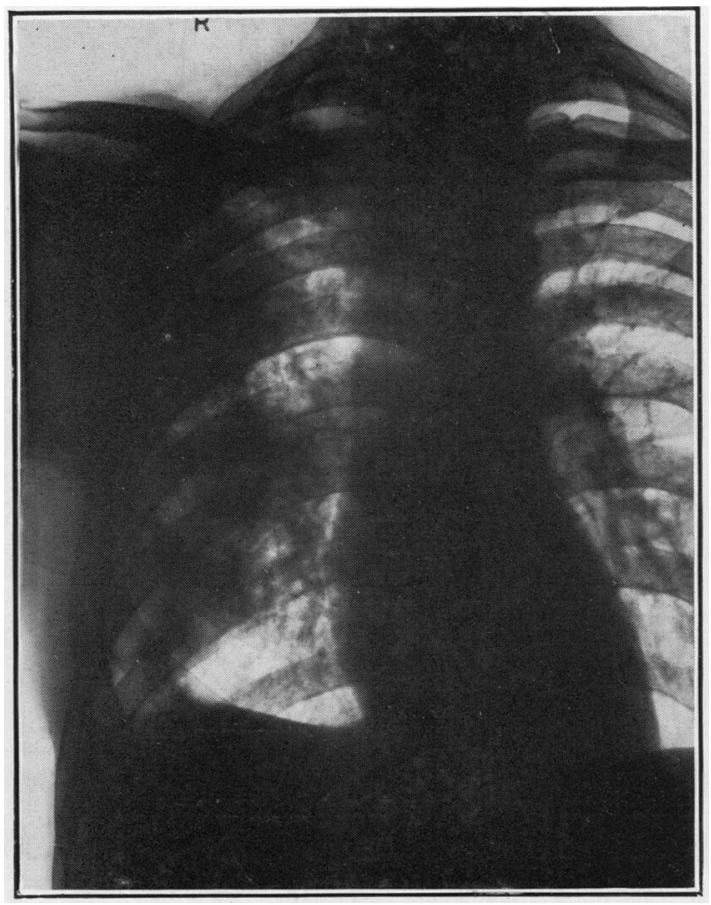

Fig. 43.

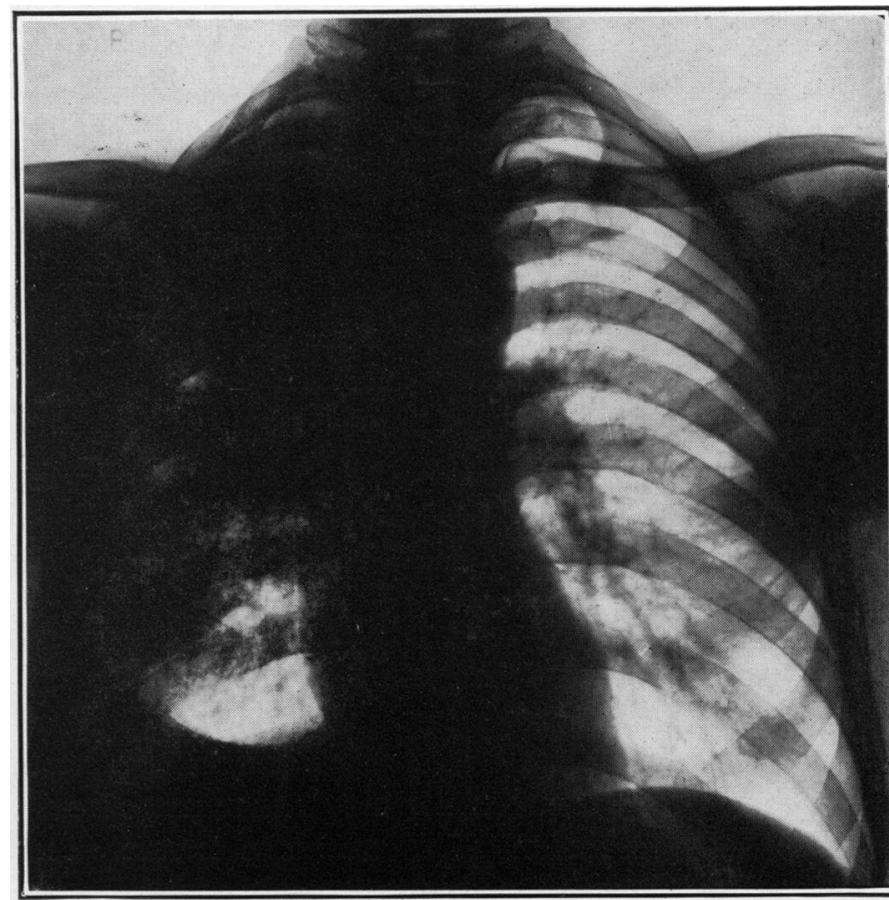

F:G. 44.

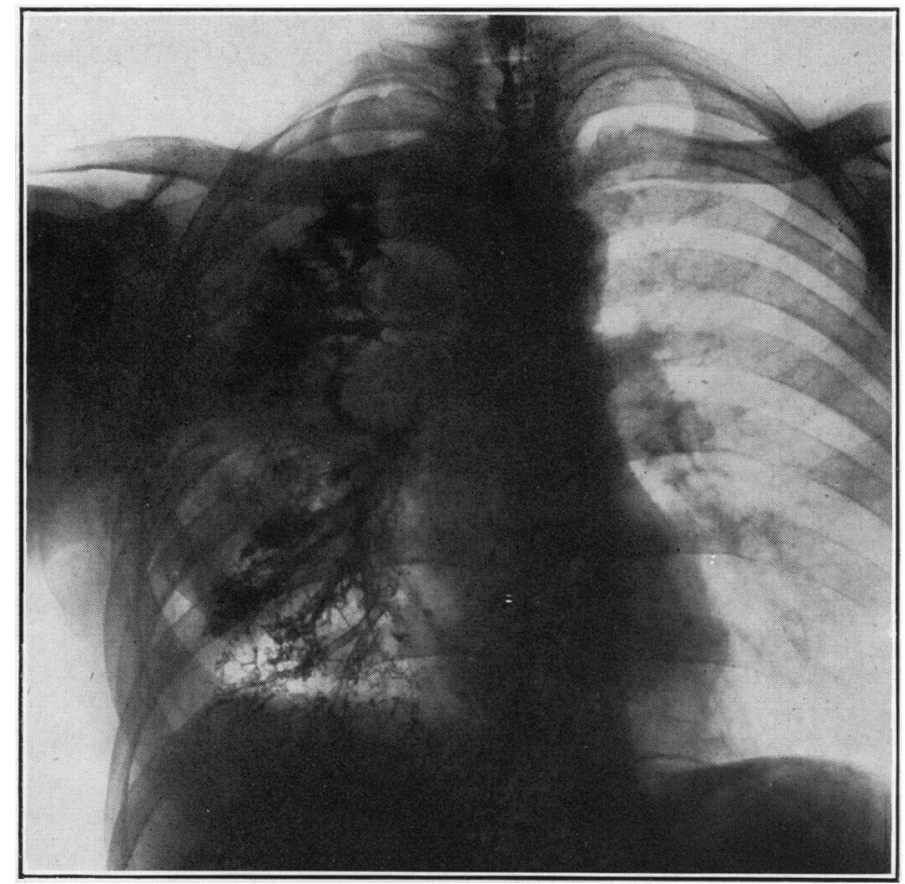

FIG. 43.-Case 6, Jan. 13, 1944. There has been resolution of the lesion in the upper part of the upper zone, but there is a cavity overlying the second interspace.

Fig. 44.-Case 6, Feb. 18, 1944. There is again further consolidation in the right upper zone with excavation. There is some suggestion of narrowing of the right main bronchus.

Fig. 45.-Case 6, March 14, 1944. Bronchogram shows considerable bronchial dilatation, and some cavity formation in the right upper lobe, a cavity in the right mid lobe, and another in the right lower lobe. 


\section{SUMMARY}

Twenty-seven cases of a condition referred to as spreading suppurative pneumonitis are analysed.

The condition is a non-specific pulmonary inflammation in which there is cavity formation. The principal clinical features are toxaemia, cough, and copious sputum. It occurs chiefly in men of middle age, and after an acute onset runs a very protracted course with exacerbations.

The extent and progress of the disease can be studied satisfactorily only by radiology. The original lesion appears as a zone of consolidation in any part of the lung. Later there is extension to contiguous areas ; this is a spreading or creeping process. Cavities develop in the affected areas, and may show characters of distension or massive ulceration.

The condition may lead to death from toxaemia, but more often there is some resolution. This resolution is rarely complete, and permanent damage to the lung is the usual end-result.

Pathological study showed many interesting features in the formation of cavities. Multiple bronchial communications were found in some instances, and epithelialization of the cavities was a feature.

No definite aetiological factor was established.

Diagnosis was difficult on account of similarity with other conditions (e.g., acute lung abscess, pulmonary tuberculosis, neoplasm). Continued observation and investigation were required before the disease could be recognized with any certainty.

There was a high mortality: 10 patients out of the 27 analysed died. No clearcut line of treatment was established. The effects of chemotherapy were uncertain. Drainage of the abscess cavities gave consistently bad results. Some cases benefited from excision of the lung, and it is felt that this form of treatment should be considered if the lesion is progressive or if severe lung damage is encountered in the later stages.

The main features of the condition have been described by other writers, though there are points of difference between their accounts and the condition as now presented. It is suggested that any classification of lung abscesses based on the foetid character of the sputum is liable to error.

A new classification of cavity formation is put forward. This divides lung abscesses into those formed as the result of (1) a pneumonic process, (2) bronchial obstruction, and (3) vascular embolism.

Six illustrative case reports of spreading suppurative pneumonitis are given. 


\section{ACKNOWLEDGMENTS}

We would like to express our gratitude to many of our colleagues, notably Mr. G. Qvist and Mr. B. R. Billimoria, in connexion with the preparation of this paper. We also acknowledge the valuable help given by Mr. A. W. Holder and Mr. W. Pereira in the provision of radiographic and pathological illustrations.

\section{REFERENCES}

Barrett, N. R. (1944). Lancet, 2, 647.

Belk, W. P. (1926). J. infect. Dis., 38, 115.

Blair, L. G. (1944). Brit. J. Radiol., 17, 169.

Collins, L. H., and Kornblum, K. (1929). Arch. intern. Med., 43, 351.

Donaldson, J. K. (1944). Surgical Disorders of the Chest, H. Kimpton, London, p. 91.

Heffron, R. (1939). Pneumonia with special reference to pneumococcus lobar pneumonia. Oxf. Univ. Press.

Houghton, L. E. (1944). Brit. J. Radiol., 17, 174.

Kessel, L. (1930). Arch. intern. Med., 45, 401.

Montgomery, G. L. (1944). Brit. J. Surg., 31, 292.

Neuhof, H., and Wessler, H. (1932). J. thorac. Surg., 1, 637.

Neuhof, H., and Touroff, A. S. W. (1936). Surg. Gynec. Obstet., 63, 353.

- (1938). Surgery, 4, 728.

- - (1940). J. Thorac. Surg., 9, 439.

- (1942). Ibid., 11, 98.

Passey, R. D., Leese, A., and Knox, J. C. (1936). J. Path. Bact., 42, 425.

Scadding, J. G. (1936). Brit. J. Tuberc., 30, 186.

(1937). Brit. med. J., 2, 956.

(1938). Proc. roy. Soc. Med., 31, 1,259.

Stats, D., and Neuhof, H. (1945). Arch. intern. Med., 76, 154.

Touroff, A. S. W., and Neuhof, H. (1941). J. thorac. Surg., 10, 618. 